(D. Eng. Thesis)

Sept. 1970

AEC Contract No. W $-7405-$ eng -48

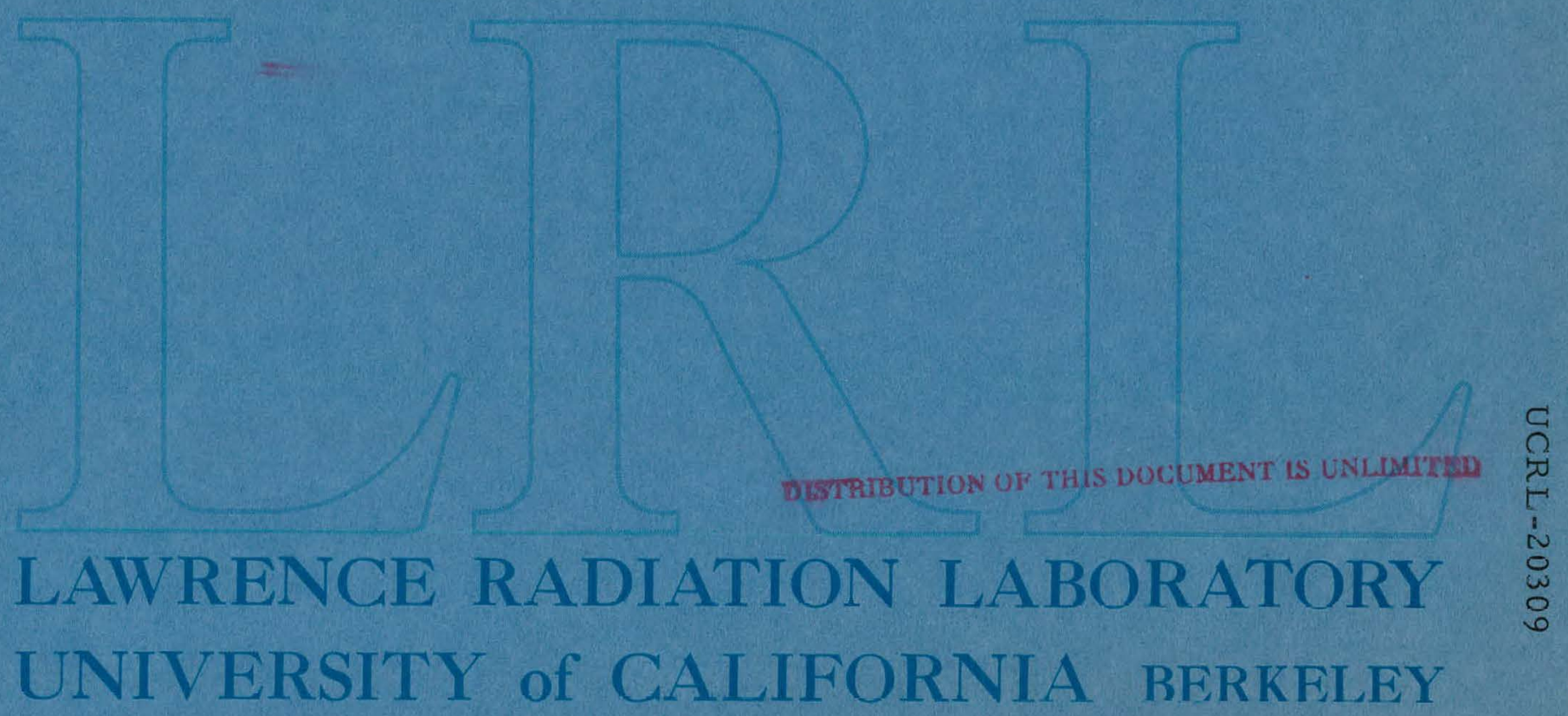




\section{DISCLAIMER}

This report was prepared as an account of work sponsored by an agency of the United States Government. Neither the United States Government nor any agency Thereof, nor any of their employees, makes any warranty, express or implied, or assumes any legal liability or responsibility for the accuracy, completeness, or usefulness of any information, apparatus, product, or process disclosed, or represents that its use would not infringe privately owned rights. Reference herein to any specific commercial product, process, or service by trade name, trademark, manufacturer, or otherwise does not necessarily constitute or imply its endorsement, recommendation, or favoring by the United States Government or any agency thereof. The views and opinions of authors expressed herein do not necessarily state or reflect those of the United States Government or any agency thereof. 


\section{DISCLAIMER}

Portions of this document may be illegible in electronic image products. Images are produced from the best available original document. 


\section{PAGES $\mathrm{i}$ to $\mathrm{ii}$ WERE INTENTIONALLY LEFT BLANK}


SINTERING AND FERROELECTRIC PROPERTIES

OF LEAD ZIRCONATE TITANATE CERAMICS

\section{CONTENTS}

ABSTRACT

I. INTRODUCTION . I

II. FXPERIMENTAL : . 4

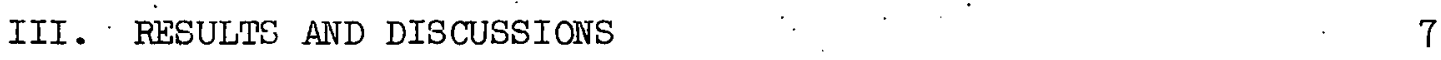

A. Stoichiometry and Lattice Vacancies 7

B. Crain Growth . . 18

C. Densification 24

D. Ferroelectric Properties 29

IV. SUMMARY AND CONCLUSIONS 41

ACKNOWLEDGMENTS

REFERENCES 
THIS PAGE

WAS INTENTIONALLY

LEFT BLANK 


\title{
SINTERING AND FERROELECTRIC PROPERTIES \\ OF LEAD ZIRCONATE TITANATE CERAMICS
}

Robert B. Atkin

Inorganic Materials Reserach Division, Lawrence Radiation Laboratory, and Department of Materials' Science and Engineering, College of Engineering, University of California

Berkeley, California

\begin{abstract}
.
Ferroelectric properties, sintering and grain growth kinetics are interpreted using crystal defect chemistry. Lattice vacancies are created thermally, by substitution impurities with the incorrect valence and by changing the stoichiometry.

Sintering follows Coble's model; bulk diffusion of vacancies from pores to grain boundaries. Oxygen vacancies are believed to be the slowest moving species.

The charge balancing vacancies associated with impurity ions cause them to be adsorbed at grain boundaries. This retards grain growth and thereby expedites densification. Impurities with an excess valence compensate for ones with a deficiency. These "paired" defects are not associated with vacancies and not adsorbed so they do not impede grain growth.

Impurities with an excess valence increase the extent of ferroelectric domain boundary motion while ions with a deficiency retard this motion. Compensation is again observed. Thermally and chemically created vacancies have a second-order effect on the ferroelectric properties.
\end{abstract}




\section{INTRODUCTION}

Lead zirconate titanate ceramics are of interest because of their outstanding ferroelectric properties. Jaffe and co-workers ${ }^{1}$ at the National Bureau of Standards found that solid solutions of lead zirconate: and lead titanate have good piezoelectric properties and they are now used extensively in electro-mechanical transducers. Land, Haerting, and. others $^{2-4}$ at Sandia Corporation showed that the optical properties of this material could be usefully modified by an electric field. This discovery made lead zirconate titanate a candidate in several types of electro-optic devices. ${ }^{5,6}$ Rapid and reversible polarization switching (ferroelectric domain reorientation) in these ceramics led to their consideration as memory storage elements. 4 For all these applications, the ceramic must be fabricated with precisely controlled ferroelectric properties.

Unfortunately this control is difficult to achieve. At high temperatures lead zirconate titanate reacts with most refractory metals and oxides. Further, it tends to decompose and lose lead oxide by evaporation. Some workers ${ }^{7-10}$ have been content to hot-press the material in oxide dies and then discard the surface layers that had reacted during hot pressing. It would be much more convenient and economical to devise a suitable sintering process. In such a process, a porous compact of the crystalline powder is heated at a temperature sutticient for surface energy forces to cause shrinkage by the elimination of pores. No external pressure is applied during sintering. Therefore, the temperature is significantly higher than required for hot pressing and grain growth and decomposition occur more rapidly. Thus the final stoichiometry and 
microstructure may be quite sensitive to the character of the starting powder and to the processing parameters during the heat treatment. In order to control the process, this sensitivity must be recognized and the importance of each processing variable should be understood.

Maintaining the correct stoichiometry is expected to be quite important. Levitt ${ }^{l l}$ fabricated specimens with slight variations ( $1 \%$ ) in their lead zirconate: lead titanate ratio and their lead oxide:zirconium. and titanium oxide ratio. He found appreciable differences in their physical and electrical properties. Webster et al. ${ }^{12}$ showed that the electromechanical coupling factor and the dielectric constant change dramatically with slight variations in. the lead content of the specimen.

Impurities may also alter the behavior of lead zirconate titanate. A number of atudies ${ }^{13-24}$ have reported the modification or ferroelectric properties by doping with certain impurities. Only a few, ${ }^{19-24}$ however, have considered the effect of these impurities upon the ultimate microstructure. Pryor ${ }^{25}$ and Nelson and Cook $^{26}$ showed that an appreciable concentration of alumina and silica was introduced by milling the powder in commercial alumina porcelain ball mills. Pryor found that alumina reduced the rate of grain growth and increased the rate of sintering. Both Pryor ${ }^{25}$ and Webster ${ }^{27}$ concluded that silica additions formed a second (liquid) phase that enhanced densification.

Some work has been done to relate the ceramic microstructure of lead zirconate titanate to its ferroelectric properties. $8,28, \ddot{2 y}$ In general, the electro-mechanical properties improve as porosity is eliminated. Properties vary significantly with average grain size and the optimum size depends upon the ultimate application. For all 
applications, this variation makes microstructure control essential for reproducibility.

The present work was undertaken to establish the effects of impurities and stoichiometry upon the microstructure development and the ferroelectric properties of lead zirconate titanate. Techniques have been devised to control impurity concentrations and to vary the stoichiometry. Densification and grain growth kinetics were measured to determine the sintering mechanism. Much of the work described here has been published by. the author or submitted for publication. In reference 30 the solid solubility and the substitutional site of aluminum in lead zirconate titanate is established. The lattice vacancies associated with niobium and bismuth substitutions are discussed in reference 31 . The effect of these and other impurities on sintering, grain growth and ferroelectric properties is described in reference 32. 


\section{EXPERIMENTAL}

In order to isolate the effects of impurities on processing and properties, a high purity, sinterable material was needed as a standard. Impurities, at the desired concentration levels, could then be added to it and the processing behavior studied. A suitable material 'as prepared. by intimately mixing appropriate amounts of lead oxide, zirconiun dioxide ${ }^{* *}$ and titanium dioxide ${ }^{\dagger}$ powders and reacting them at $850^{\circ} \mathrm{C}$ in a covered platinum crucible. This reacted material was crushed in a lucite mortar and pestle, then ground in a vibratory ball mill with lucite grinding media. This reduced the crystal size to less than one micron and the lucite contaminate could be completely removed by air oxidation at $400^{\circ} \mathrm{C}$. The desired impurities were then added as aqueous solutions. The impurities which are normally added to improve electrical. properties (niobium and bismuth), were added prior to calcination to better stimulate "doping." Spectrographic analysis of the standard material showed it contained $0.05 \mathrm{wt} \% \mathrm{Al}_{2} \mathrm{O}_{3}, 0.02$ wt\% $\mathrm{CaO}, 0.02 \mathrm{wt} \% \mathrm{SiO}_{2}$ and $0.002 \cdot \mathrm{wt} \% \mathrm{MgO}$.

Specimens were formed by pressing the powders into pellets in a steel die. These pellets were pre-fired at $800^{\circ} \mathrm{C}$ for $\mathrm{l}$ hour. This incrcaced thcir atrongth sufficiently to allow measurements of lleir initial dimensions and weight. No significant shrinkage occurred during pre-firing. The welghed and measured pellets were loosely covered with packing powder ${ }^{\#}$ in a platinum crucible with a tight fitting lid. The

\footnotetext{
* Baker, reagent grade.

* Wah Chang, reactor grade.

$+\quad B \& A$, reagent grade.

\# The powder is to isolate the specimens and to provide the correct partial pressure of lead oxide as discussed below.
} 
crucible was evacuated and refilled with the desired gas. Oxy.gen and mixtures of oxygen and nitrogen were used. The crucible was then heated in an atmosphere furnace which had the same gas composition. At first, the specimens were set in the furnace and heated to the sintering temperature, but this resulted in a slow heating rate and consequently, considerable uncertainty about the effective time at temperature. Later, a technique was devised to insert and withdraw the crucible from the hot zone of the atmosphere furnace. Using this procedure, the specimens reached the sintering temperature in less than two minutes and cooled below $600^{\circ} \mathrm{C}$ in about 10 seconds. The subsequent rate of cooling was reduced to avoid fracture at the curie transformation around $350^{\circ} \mathrm{C}$.

The density of the sintered specimens was measured by immersion in mercury or by calculating the specimen's volume from its dimensions and measuring its weight. The geometric technique was used for determining the initial density to avoid contamination wilh mercury and it was faster and more accurate than the immersion method. Mercury immersion wค.s necessary for irregularly shaped pieces; e.g., broken, cracked or warped pellets.

Grain sizes were measured from scanning electron micrographs of surfaces that were polished and chemically etched, fracture surfaces, and original pellet surfaces that were thermally etched during sintering. These measurements were in agreement except when the specimen contained a volatile grain growth inhibitor. Bismuth additions impeded grain growth in the pellet's interior but not at its surface. It is believed that bismuth was depleted from the surface by evaporation so grain growth 
was not effectively impeded there. ' Interior grain sizes were used for bismuth doped materials. The line intercept method ${ }^{33}$ was used. Reported grain sizes are 1.5 times the average chord length. More than 200 grains were counted for each determination.

High field ferroelectric measurements were made to determine the ease and extent of הnmain renrientation. Spccimeno were piefared by lapping the pellet faces flat and parallel and painting ${ }^{* *}$ on silver electrodes. An alternating electric field (peak approximately \pm 100 volts $/ \mathrm{mil}$ or $40 \mathrm{KV} / \mathrm{cm}$ ) was applied and the resulting dielectric polarization was recorded. Hysteresis loops were mun at 60 and $0.01 \mathrm{hz}$. The magnitude of the maximum polarization is proportional to the extent of domain boundary motion which is sensitive to the concentration of lattice vacancies. 35

* This phenomenon was observed with magnesia doped alumina. 35 Magnesia. loss at the surface is believed to allow wore rapid growth there. ** Silver conducting Paint, Micro-Circuits Co. 
III. RESULTS AND DISCUSSIONS'

\section{A. Stoichiometry and Lattice Vacancies}

Lead zirconate titanate has two components that are quite volatile at the sintering temperature, lead and oxygen. The equilibrium vapor pressures of zirconium, titanium and their oxides are low at $1200^{\circ} \mathrm{C}$, so these components are not readily lost by evaporation. In order to establish and maintain the desired stoichiometry, lead zirconate and lead titanate must be heat treated in an atmosphere which contains the correct oxygen and lead oxide partial pressures. Equilibrium of the vapor-phase reaction

$$
\mathrm{PbO}_{\text {vapor }} \stackrel{\rightarrow}{\leftarrow} \mathrm{Pb}_{\text {vapor }}+1 / 2 \mathrm{O}_{2}
$$

is assumed so any two vapor pressures fix the lead and the oxygen activity.

The phase diagrams for lead oxide-titanium oxide ${ }^{36}$ and lead oxidezirconium oxide ${ }^{36}$ are shown in Fig. 1. Both were determined in air. The. corresponding lead oxide activity composition diagrams are also shown. These were constructed for $1200^{\circ} \mathrm{C}$ using the following assumptions:

(I) The lead oxide activity coefficient is equal to unity in the liquid phases. This is Raoult's Law for the lead oxide rich compositions; the activity of pure lead oxide is taken as unity.

(2) The lead oxide activity decreases linearly with composition in the solid solution regions (Henry's Law).

(3) The decomposition vapor pressures of lead liluarate and lead zirconate as measured by Knudsen cell experiments, 37 were converted to 

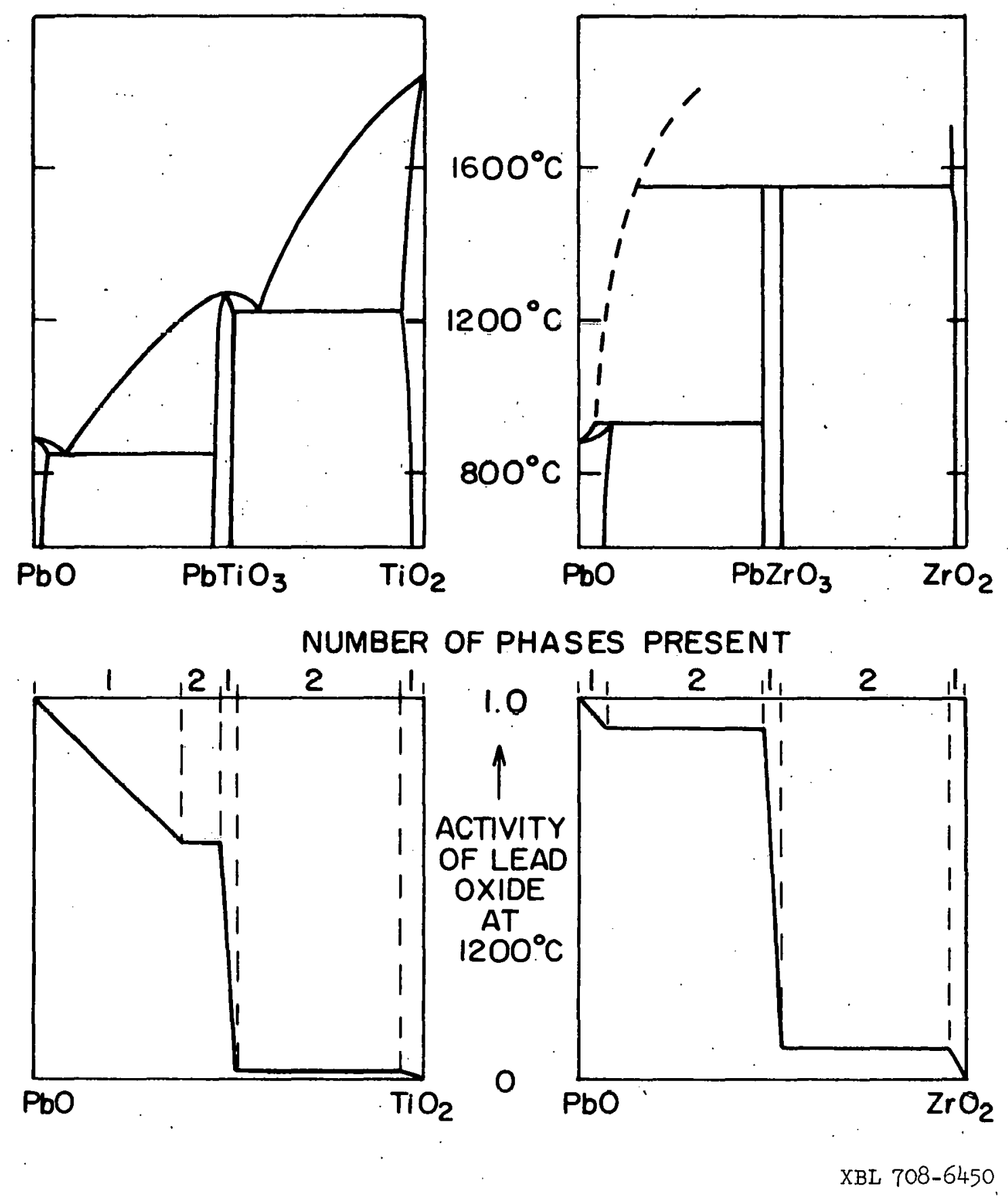

Fig. 1. The binary phase diagrams indicate that the perovskite compounds may exist over a range of composition. The activity:composition diagrams show the limiting lead oxide activities for the single phase regions. 
activities by dividing by the vapor pressure above pure lead oxide at the

same temperature.

At $1200^{\circ} \mathrm{C}$ lead zirconate and lead titanate are completely miscible. 36,38 Their solid solutions exist over a considerable range of $\mathrm{PbO}:(\mathrm{Zr}, \mathrm{Ti}) \mathrm{O}_{2}$ ratios, each corresponding to a different lead oxide activity. The metal:oxygen ratio may also vary as indicated on the quaternary phase diagram sketch in Fig. 2. This latter variance is believed to be primarily accommodated by lattice vacancies. High concentrations of interstitials is unlikely because the perovskite unit cell (Fig. 3) is already efficiently packed and the possible interstitial sites are bounded by both positive and negative ions. The crystal structure may be thought of as a cubic close packed, ordered arrangement of lead and oxygen. The octahedral site at the center of the cell is bounded by six oxygens and occupied by either zirconium or titanium. The other three octiahedra are formed each by four anions and two lead ions; they are unoccupied. The tetrahedral sites are bounded by one lead and three oxygens. These are also empty. Alternatively, the structure may be compared to that of rhenium oxide $\left(\mathrm{ReO}_{3}\right) .39$ Then the structural units are ( $\mathrm{Zr}, \mathrm{Ti}) \mathrm{O}_{6}^{=}$octahedra. They are bound together at corners as each oxygen is coordinated with two tetravalent ions. Divalent lead enters the 12 fold sites between octahedra to maintain electroneutrality. This description implies that crystal may become substantially deficient in lead if another charge halancing mechanism is operative. Such mechanisms might be the localization of electron holes at the vacancy,

* This type of A site vacancy is not charged with respect to the undisturbed lattice and will be designated as $V_{A}$. Uncharged $B$ site and oxygen vacancies will be represented by $V_{B}$ and $V_{O}$, respectively. The concentration of the defect will be indicated by square brackets [ ]. 


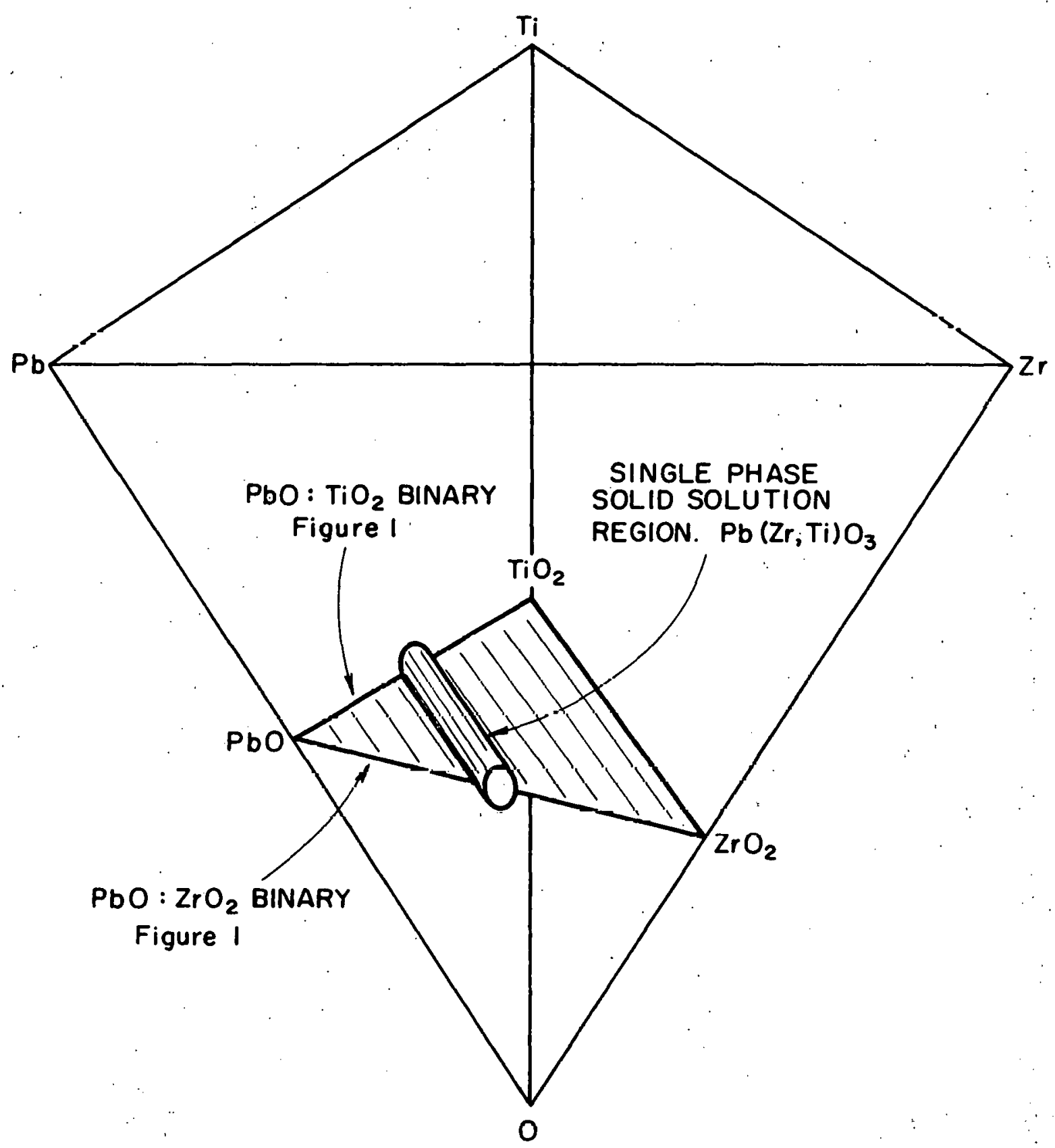

XBI. $708-6449$

Fig. 2. Schematic $\mathrm{Pb}: \mathrm{Zr}: \mathrm{Ti}: 0$ phase diagram showing that the oxygen: metal ratio may also vary. 


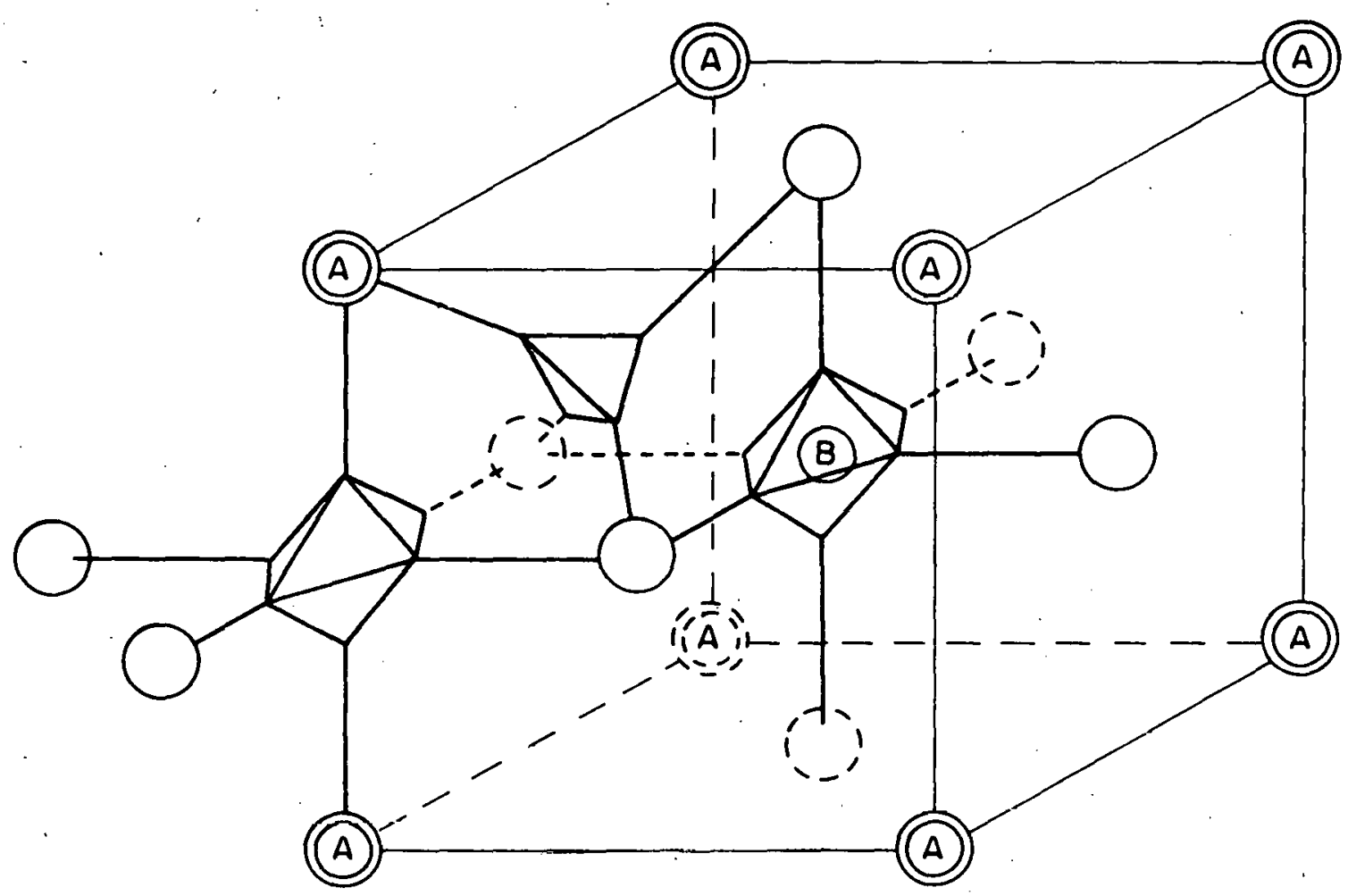

XBL $708-6448$

Hig. 3. 'l'he perovskite unit cell with possible interstitial sites indicated. 
the formation of an anion. vacancy at an adjacent' lattice site, or the substitution of an ion with the incorrect valence on an adjacent site.

Clearly the concentration "of lattice vacancies changes with the activity of lead oxide. With the oxygen pressure fixed, the crystal will saturate with A-site vacancies when the lead oxide activity is sufficiently low. Subsequent loss of lead oxide will result in the formation of a second phase, but the lead oxide activity of the system will remain constant. These lower limit activities were calculated from reported 37 vapor pressure measurements of mixtures of $\mathrm{Pb}(\mathrm{Zr}, \mathrm{Ti}) \mathrm{O}_{3}$ and $(\mathrm{Zr}, \mathrm{Ti}) \mathrm{O}_{2}$. They are plotted in Fig. 4. The decomposition pressure (presumed to be lead oxide pressure) is greater for $\mathrm{PbZrO}_{3}$ than for $\mathrm{Pb}(\mathrm{Zr} .5 \mathrm{Ti} .5) \mathrm{O}_{3}$. Thus when a specimen of $\mathrm{Pb}(\mathrm{Zr} \cdot 5 \mathrm{TI} .5) \mathrm{O}_{3}$ 1s buried in a mixture of lead zirconate plus zirconia and heat treated at a high temperature, vapor transport of . lead oxide will allow the specimen to "equilibrate" with the packing powder. Transport of titania and zirconia is negligible at $1200^{\circ} \mathrm{C}$ so the zirconium-titanium ratio of the specimen will not change. The specimen will simply lose lead oxide until its activity is approximately 0.05 . Some of the zirconia in packing powder will react with the expelled lead oxide to form more lead zirconate and the lead oxide activity of the system will remain at 0.05 . Loss of lead oxide from the system (say by evaporation to the surrounding) will cause some of the lead zirconate to decompose, but the lead oxide activity does not decrease.

This "buffered" situation is also possible for high lead oxide activities. The lead oxide activity of mixtures of $\mathrm{Pb}(\mathrm{Zr}, \mathrm{Ti}) \mathrm{O}_{3}$ and lead oxide rich liquid were calculated from the $\mathrm{PbO}: \mathrm{ZrO}_{2}: \mathrm{TiO}_{2}$ ternary phase 


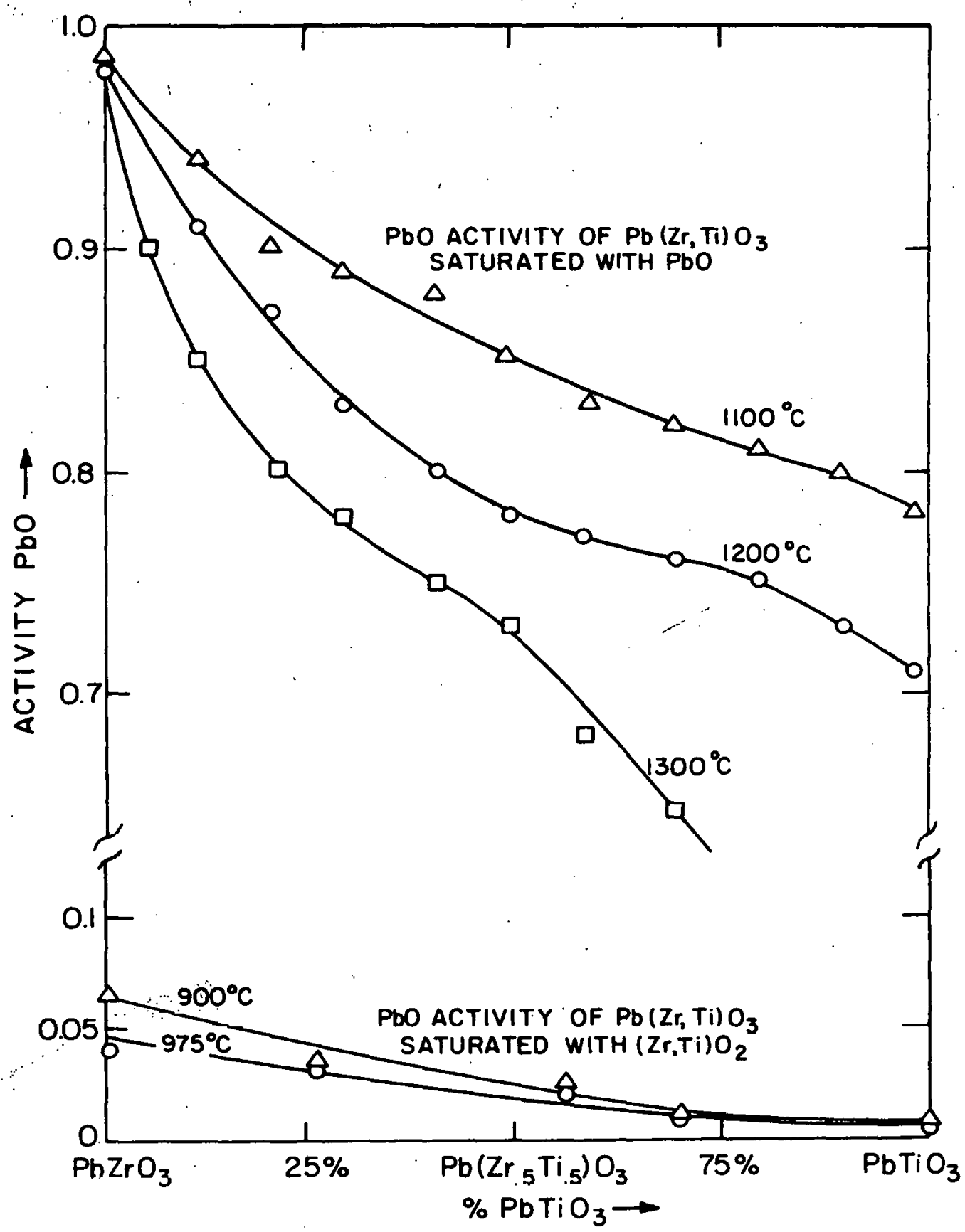

XBL $708-6454$

Fig. 4. Limiting lead oxide activities for single phase $\mathrm{Pb}(\mathrm{Zr}, \mathrm{Ti}) \mathrm{O}_{3}$. 
diagram. 37 Again Raoult's Law was assumed for the liquid and pure lead oxide (liquid) was taken as the standard state. Those activities are also plotted in Fig. 4. Now consider a specimen packed in a mixture. of lead titanate and lead oxide. After equilibration with respect to lead oxide, the activity of the system will remain at approximately 0.7 (at $1200^{\circ} \mathrm{C}$... see Fig. 3). Loss of lead oxide from the system will simply reduce the quantity of the lead oxide rich liquid in the packing powder. During equilibration, the specimen remains single phase, but its lead oxide activity is increased to approximately 0.7 . This change is accomplished by increasing the lead concentration of the crystal, i.e., reducing the concentration of lead vacancies.

Equilibration experiments were conducted with both types of packing powder to establish the width of the single phase region. Specimens of $\mathrm{Pb}\left(\mathrm{Zr} .{ }_{5} \mathrm{Ti} .{ }_{5}\right) \mathrm{O}_{3}$ slightly deficient in lead oxide were weighted, equilibrated with "buffered" packing powders with high and Low Lead oxide activities in one atmosphere of oxygen, and then reweighed. The results of these experiments at $1150^{\circ} \mathrm{C}$ is shown in Fig. 5. If the difference in specimen weight at lead oxide activities of 0.7 and 0.05 is assumed entirely due to the difference in the concentration of lead vacancies, then the saturation concentration of these defects is calculated to $5.6 \times 10^{20}$ per cubic centimeter. This concentration corresponds to approximately $4 \%$ of the lead atoms missing. Allowances for simultaneous changes in the concentrations of $B$ site and oxygen vacancies were not included in this calculation. Significant changes in either of those concentrations would mean the actual saturation concentration is somewhat less than $5.6 \times 10^{20}$ per cubic centimeter. 


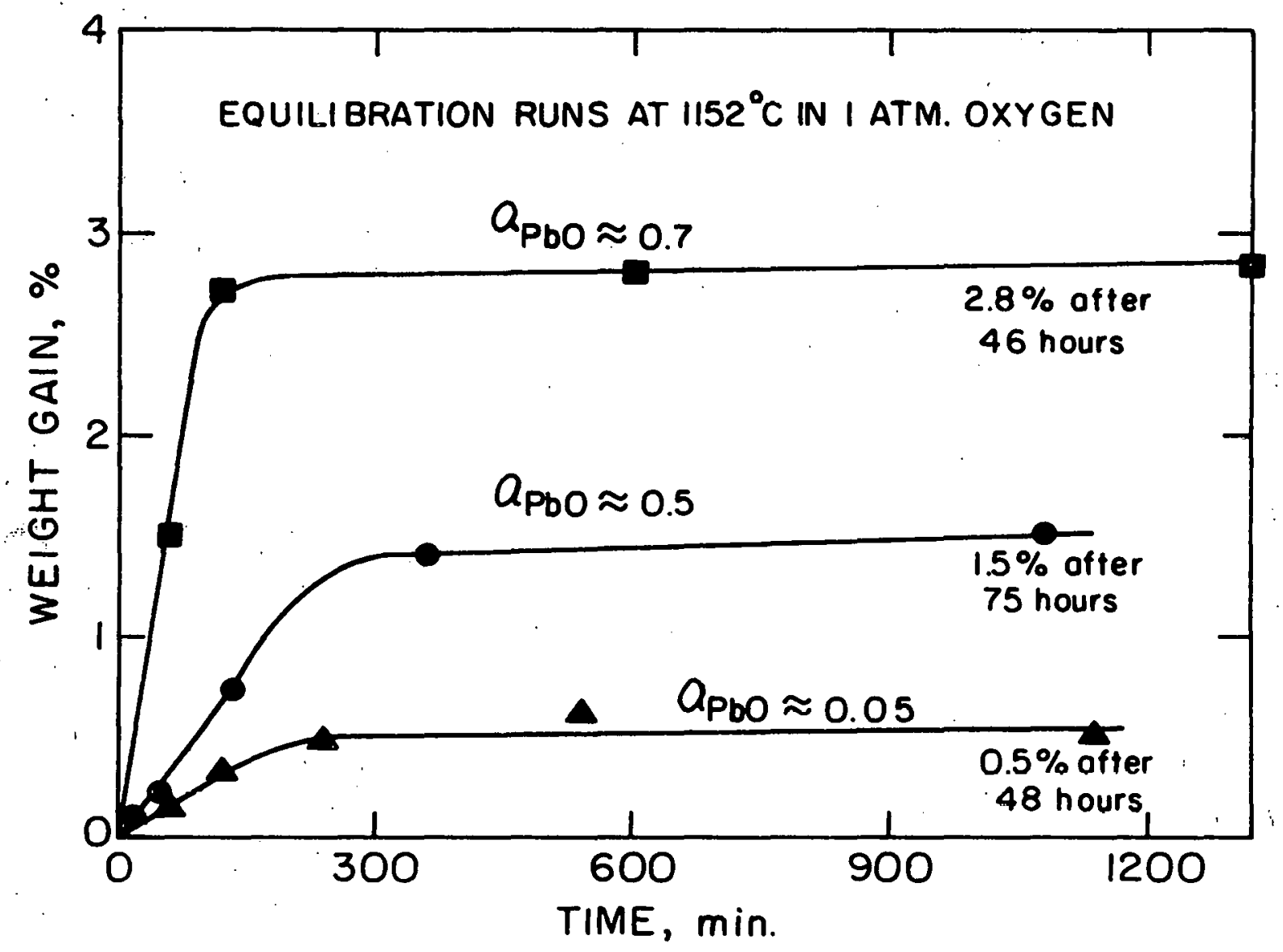

XBL 708-6453

Fig. 5. Vapor-phase equilibration experiments. 
It is also possible to fix the lead oxide activity at intermediate values. The specimen is packed in single-phase lead zirconate titanate powder in a closed cell. A small amount of lead oxide is lost by the specimen and packing powder to establish the atmosphere inside the cell. This loss, of course, reduces the lead oxide activity. Hence the final stoichiometry of the specimen will be sensitive to the initial lead oxide concentration in the system, the volume of the cell, and any vapor losses from it. Equilibration experiments with this type of packing powder were also conducted and shown in Fig. 5. The lead oxide activity of stoichiometric lead zirconate-titanate packing powder was taken as 0.5

The oxygen activity has been assumed constant, but this requirement may be relaxed. When the partial pressure of oxygen in the atmosphere is reduced, the specimen will lose that component in order to achieve the correct oxygen activity

$$
O_{\text {solid }} \stackrel{*}{*} / 2\left(\mathrm{O}_{2}\right)_{\text {vapor }}+\mathrm{V}_{0}
$$

This same type reaction might have been considered for lead:

$$
\mathrm{Pb}_{\text {solid }} \stackrel{\leftrightarrow}{\stackrel{\mathrm{Pb}}{\text { vapor }}}+\mathrm{V}_{\mathrm{Pb}}
$$

Both these reactions alter the stoichiometry.

Chemical interaction between the several types of vacancies in the solid should also be considered. Schottky equilibrium is probably a reasonable assumption. 


$$
\left[\mathrm{v}_{A}\right]\left[\mathrm{v}_{\mathrm{B}}\right]\left[\mathrm{v}_{0}\right]^{3}=\mathrm{K}_{\mathrm{S}}
$$

where $K_{S}$ is a temperature dependent constant. This equilibrium may be obtained by the introduction (or exsolution) of vacancy quintuplets at free surfaces or grain boundaries:

$$
(A B O)_{\text {solid }} \rightleftarrows(A B O)_{\text {surface }}+v_{A}+V_{B}=3 V_{O}
$$

The stoichiometry is not changed as this reaction proceeds; however, the crystal's volume increases because new unit cells are formed as $\mathrm{ABO}_{3}$ is transferred from the. solid to the surface. The vacancies (one $V_{A}$, one $V_{B}$ and three $V_{0}$ ) that are created by the event then diffuse into crystal, thereby increasing the concentration of each type. At equilibrium, the termary product of the vacancy activities $\left(\boldsymbol{a}_{V_{A}} \cdot \boldsymbol{a}_{V_{B}} \cdot \boldsymbol{a}_{V_{0}}^{3}\right.$ ) is proportional to the activity of $\left(\mathrm{ABO}_{3}\right)_{\text {solid }}$ divided by the activity of $\left(\mathrm{ABO}_{3}\right)_{\text {surface }}$. Assuming this ratio is unit and that activities are proportional to concentrations, Eq. (4) 1s obta1ned. Equations (2), (3), and (4) pred ct that lowering the lead activity, at a fixed oxygen pressure, will increase $\left[\mathrm{v}_{\mathrm{A}}\right]$, decrease $\left[\mathrm{v}_{\mathrm{B}}\right]$, and leave $\left[\mathrm{V}_{0}\right]^{*}$ unchanged. With the lead activity constant, lowering the oxygen partial pressure should increase $\left[\mathrm{V}_{0}\right]$, decrease $\left[\mathrm{V}_{\mathrm{B}}\right]$ and not alter $\left[\mathrm{V}_{\mathrm{A}}\right]$.

Doping is another mechanism for introducing vacancies. When an ion with the incorrect valence enters the lattice, charged vacancies may form to maintain local electroneutrality. This phenomena has been established ${ }^{31}$ when $\mathrm{Bi}^{+3}$ and $\mathrm{Nb}^{+5}$ substitute for $\mathrm{Pb}^{+2}$ and $\mathrm{Ti}^{+4}$ respectively. 
Lead zirconate titanate powder was mixed with varying amounts of bismuth trioxide and niobium pentoxide, pressed into specimens, and equilibrated with a large volume of packing powder which had the same initial stoichiometry as the lead zirconate titanate powder in the specimens. The changes in specimen weight that were observed during equilibration corresponded to: (1) replacement of three lead atoms by two bismuth atoms, and (2) creation of two unit cells for every two niobium atoms added with one cell deficient in lead. In each case one lead vacancy is introduced for every two substituted ions. This indicates that each lead vacancy created to maintain electroneutrality has an effective charge of minus two. Aluminum atoms have been shown to enter B lattice sites ${ }^{30}$ and are assumed to create charged anion vacancies. This assumption cannot be easily confirmed by weight change experiments because of the small atomic mass of oxygen.

\section{B. Grain Growth}

During the sintering heat treatment, grain growth occurs. The grain boundary mobility was found to be sensitive to the presence of doping ions (ones which formed charged vacancies) but was not sensitive to the concentration of uncharged vacancies.

When grain growth is limited by the grain boundary mobility, the rate should be inversely proportional to the average radius of curvature of that boundary. 40 This curvature is proportional to the grain size, and the relation can be integrated to give:

$$
G^{2}-G_{0}^{2}=k t
$$


or

$$
G \simeq k^{\prime} t^{l / 2} \text { for } G_{O} L L^{G}
$$

The average grain size, $G$, is equal to $G_{0}$ when the time, $t$, is equal to zero. The constants, $k$ and $k^{\prime}$, depend upon the temperature and the boundary mobility.

If the grain boundary is pinned by discrete second-phase particles (including pores), then the rate of grain growth is limited by the rate of coalescence of the second phase. The coalescence of a dispersed second phase has been shown to proceed proportionally to the cube root of time, ${ }^{41}$ leading one to expect similar kinetics for grain growth.

$$
G-k^{\prime \prime} t^{1 / 3}
$$

Kingery and Francois applied this relation to pore limited grain growth in uranium dioxide. ${ }^{42}$ Their theory was later extended by Nichols. 43

Both types of kinetics were observed with lead zirconate titanate (Fig. 6). The undoped material has a high boundary mobility so pore. coalescence is rate limiting. The grain size is proportional to the cube root of time, and the rate constant, $k^{\prime \prime}$, has an apparent activation energy of $96 \mathrm{kcal} / \mathrm{mole}$. When the material is doped with bismuth, niobium or aluminum, the rate of grain growth is reduced. Similar grain inhibitation has been reported for lead zirconate titanate doped with $\mathrm{Fe}^{+3^{24}}$ (probably substituted on B sites), and for barium titanate doped with $\mathrm{Ta}^{+5^{44}}$ (B site) and $\mathrm{Sm}^{+3}$. (A site). The kinetics for lead zirconate 


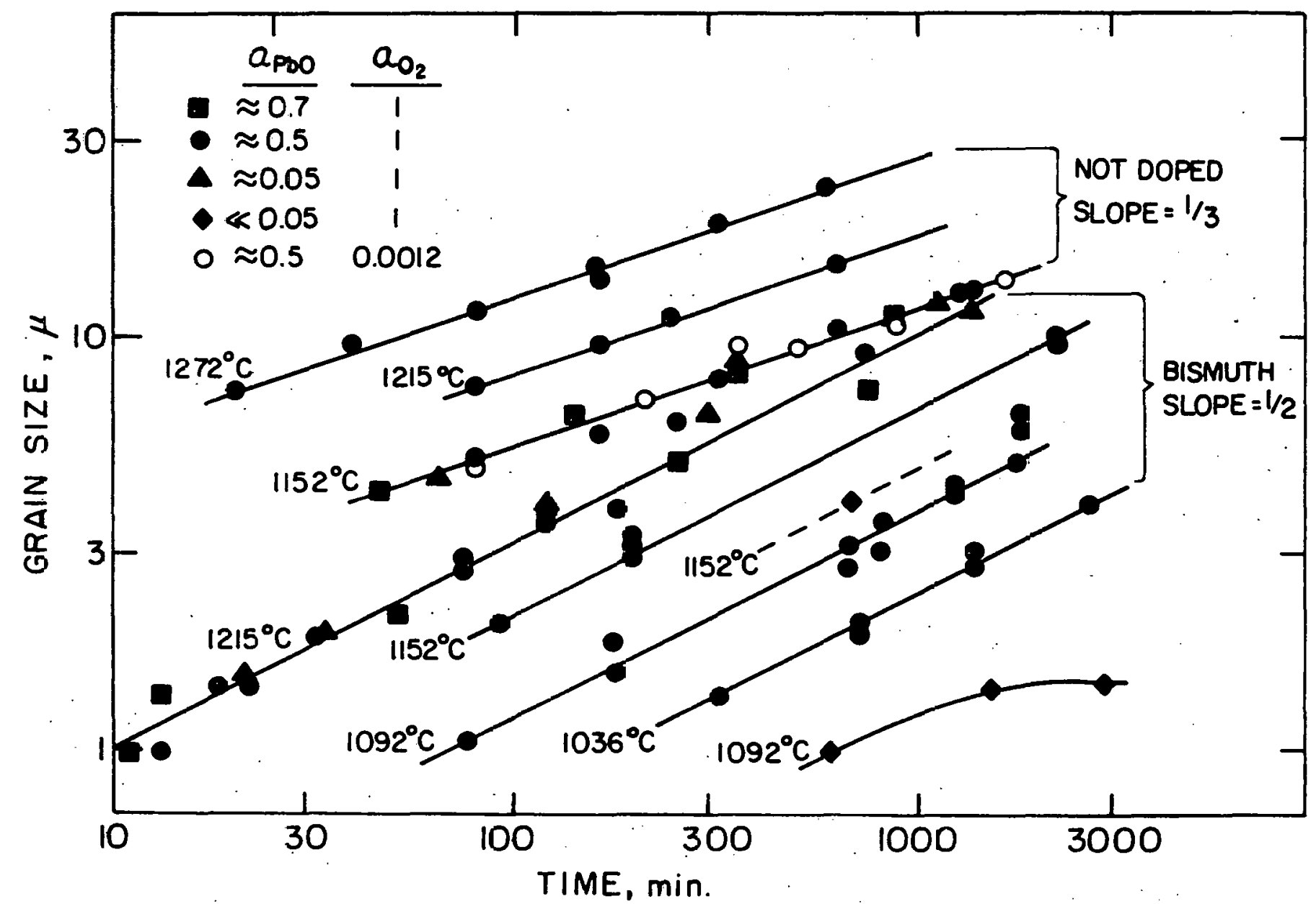


titanate doped with two atomic percent bismuth follows'Eq. (6). It is believed that the doping ions concentrate near the grain boundaries and substantially reduce their mobility. When the boundary moves, it must drag the excess (adsorbed) impurities along with it, as depicted in Fig. 7. This mechanism for reducing grain boundary mobility has been studied theoretically and experimentally as it applies to the recrystallization of metals. ${ }^{46-48}$ Jorgensen 49,50 and Westbrook ${ }^{50}$ used this model to explain how magnesia inhibits grain growth in alumina and allows sintering to thecretical density. Jorgensen and Anderson ${ }^{51}$ later showed that $\mathrm{Th}^{+4}$, dissolved in yttria, was adsorbed at grain boundaries and substantially reduced the rate of grain growth, thereby permitting complete densification. When the thoria content exceeded the solid solubility limit, the grain growth rate was further decreased and second phase particles were observed at grain boundaries. Doping lead zirconate titanate with substitutional ions that have the incorrect valence reduces - : $:$ the boundary mobility so that it is slow relative to pore coalescence and hence rate limiting as indicated by the kinetics.

Doping with bismuth and aluminum or with niobium and aluminum did not effectively impede grain growth. The combination of bismuth and niobium was more effective than either alone (see Fig. 8 and ref. 32). These observations imply that doping ions are associated with the charge balancing vacancies and that these vacancies are responsible for the attraction between the defects and the grain boundary. Compensating doping ions, e.g., $\mathrm{Nb}^{+5}$ and $\mathrm{Nl}^{+3}$ replacing two $\mathrm{Ti}^{+4}$, are believed associated on adjacent lattice sites without charged lead or oxygen vacancies. They are not attracted to the boundary, hence cannot reduce 


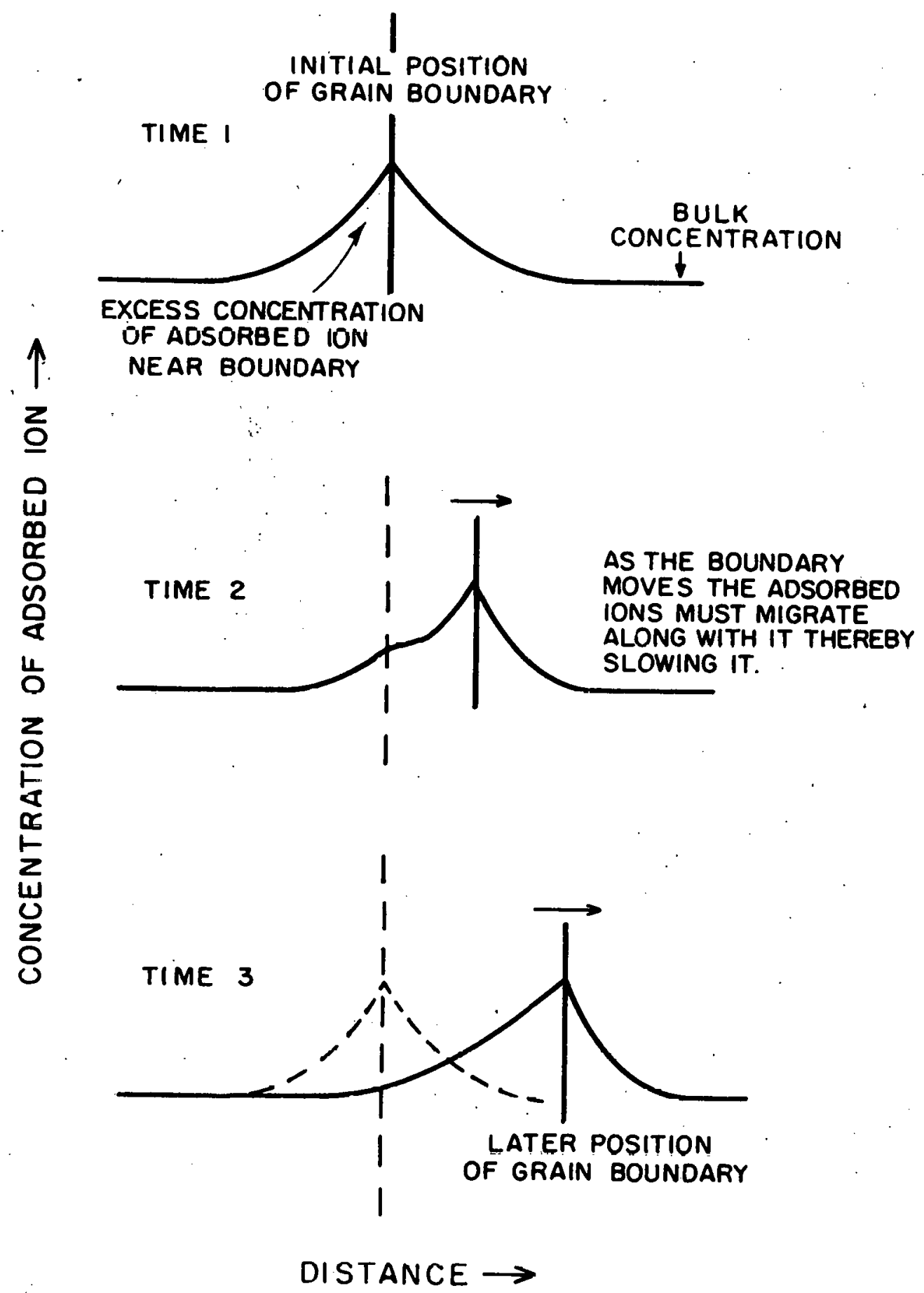

XBL 708-6451

Fig. 7. Mechanism by which adsorbed impurities impede grain boundary motion. 

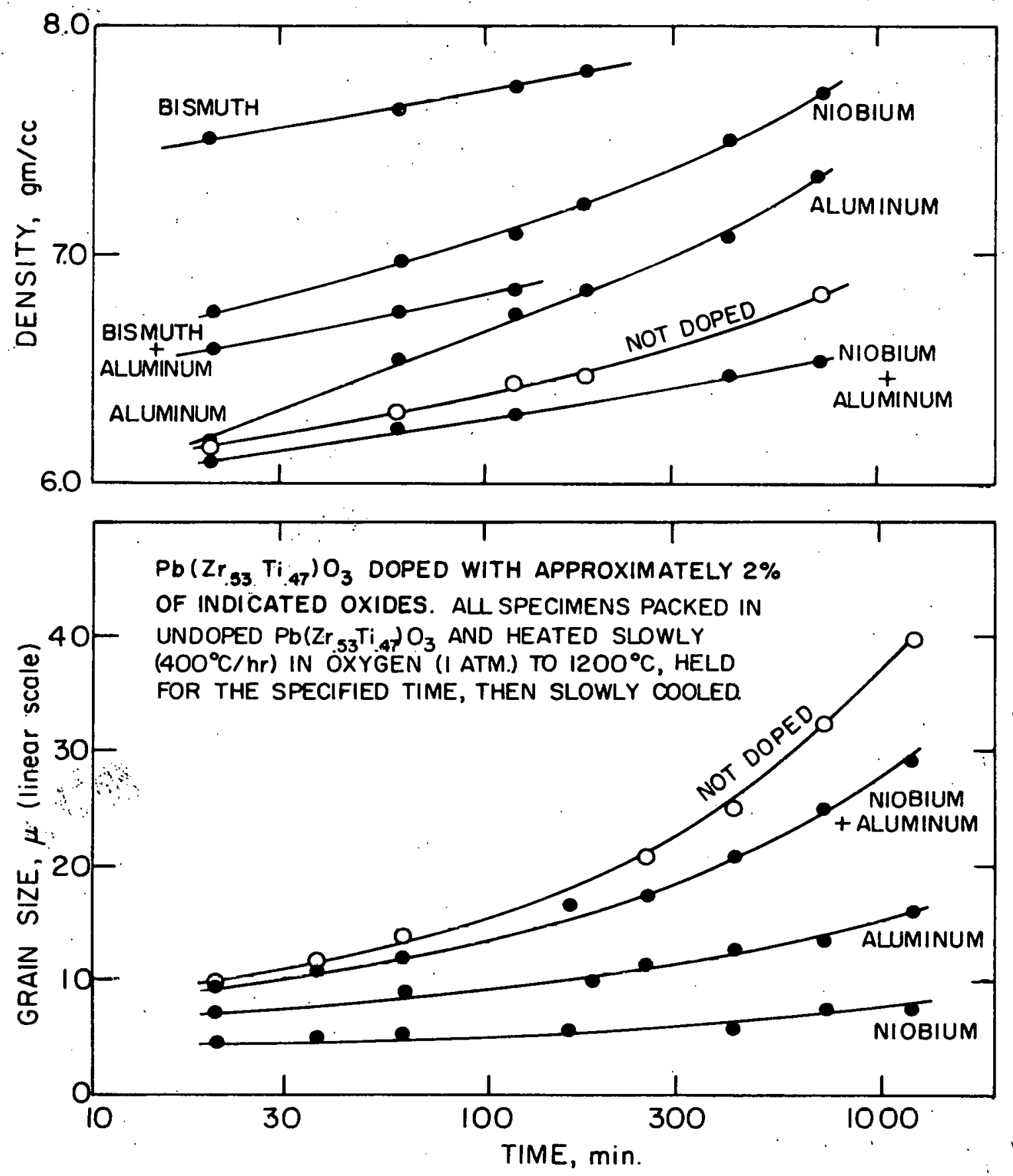

XBL 708-6455

Fig. 8. Effects of impurities on sintering and grain growth. 
its mobility.

Second phases, solid or liquid, may occur when the lead oxide activity is excessively high or low or when the impurity concentration exceeds saturation. Silicon dioxide additions in excess of saturation react with lead oxide (from.the vapor) to form a liquid phase. 25,26 l'his Lqquid expedites grain growll. 32 Buric uxide aditions form a liquid that changes the grain morphology to cubes (Fig. 16c).

The kinetic measurements shown in. Fig. 6 were obtained by heat treating specimens, initially deficient in lead oxide, in atmospheres of various lead oxide activities, as indicated by the legend. The grain growth rate is virtually independent of the lead and oxygen activity so long as single phase lead zirconate titanate exists. The bismuth doped material at very low'lead oxide activity, presumably beluw lle luwer limit for a single phase, showed slower grain growth. It is suspected liul a second solid phase was present, inhibiting boundary motion. At higher temperatures, where the solubility should be greater, the deviation was less pronounced.

\section{C. 'Densification}

Coble 52,53 has developed a model to describe the intermediate and final stages of sintering single phase crystalline solids. It is primarily concerned with densification resulting from the shrinkage of pores as lattice vacancies diffuse from them to grain boundarles. Other pussible later stage shrinkage mechanisms (e.g., transport of atoms along grain boundaries to pore by grain boundary diffusion or by plastic flow) have not received much theoretical or experimental attention. Undoped lead zirconate titanate followed the kinetics predicted by the Coble 


$$
\begin{gathered}
-25- \\
=
\end{gathered}
$$

model. The density increased linearly with the logarithm of time (Fig. 9), and the grain size increased as. the cube root of time (Fig. 6). During densification, cylindrical and spherical pores were observed at grain boundaries. The effective diffusion coefficient, D, was calculated using the Coble equation:

$$
\frac{d \rho}{d t}=315-\frac{\operatorname{sog} D}{K T G^{3}}
$$

where $\frac{d \rho}{d t}$ is the instantaneous densification rate, $K$ is the Boltzman's constant, $T$ is the absclute temperature, $\Omega$ is the atomic volume (assumed to be $1.1 \times 10^{-22} \mathrm{~cm}^{3}$ ) and $\gamma$ is the surface energy (assumed to be $10^{3}$ ergs $\left./ \mathrm{cm}^{2}\right)$. D is plotted in Fig. 10 vs 1000/RT to yield an apparent activation energy of approximately $70 \mathrm{kcal} / \mathrm{mole}$. This energy is approximately twice that observed by Haertling ${ }^{9}$ for pressure sintering $\mathrm{Pb}\left(\mathrm{Zr} .65 \mathrm{Ti} .3_{5}\right) \mathrm{O}_{3}$ doped with $2 \%$ bismuth. The actual values of the diffusion coefficients he calculated using the Nabarro-Herring equation are, however, within an order of magnitude of those calculated from the Coble equation (Fig. 10) in this study.

Increasing the lead activity with the pressure of oxygen held at one atmosphere did not alter the densification behavior. A change in stoichiometry (increase in $\left[\mathrm{V}_{\mathrm{B}}\right]$, decrease in $\left[\mathrm{V}_{\mathrm{A}}\right]$, and $\left[\mathrm{V}_{0}\right]$ constant) was verified by measured weight grains. Specimens in different atmospheres gained weight at different rates during the first 200 minutes of sintering and then remained at constant but different stoichiometries during the subsequent sintering (Fig. 5). The densificalion was 


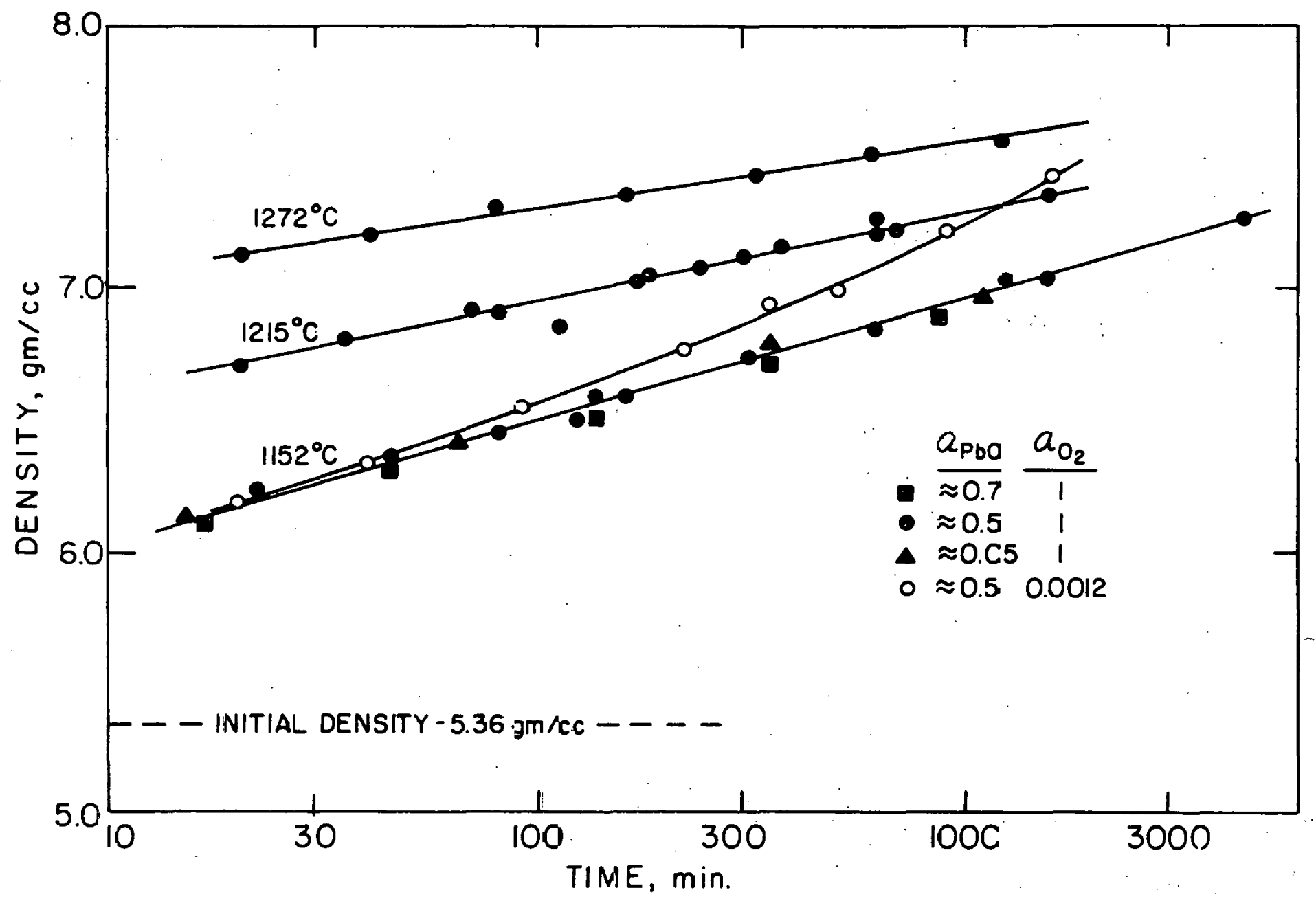

Fig. 9. The effect $0=$ atmosphere on the sintering of undoped material. 


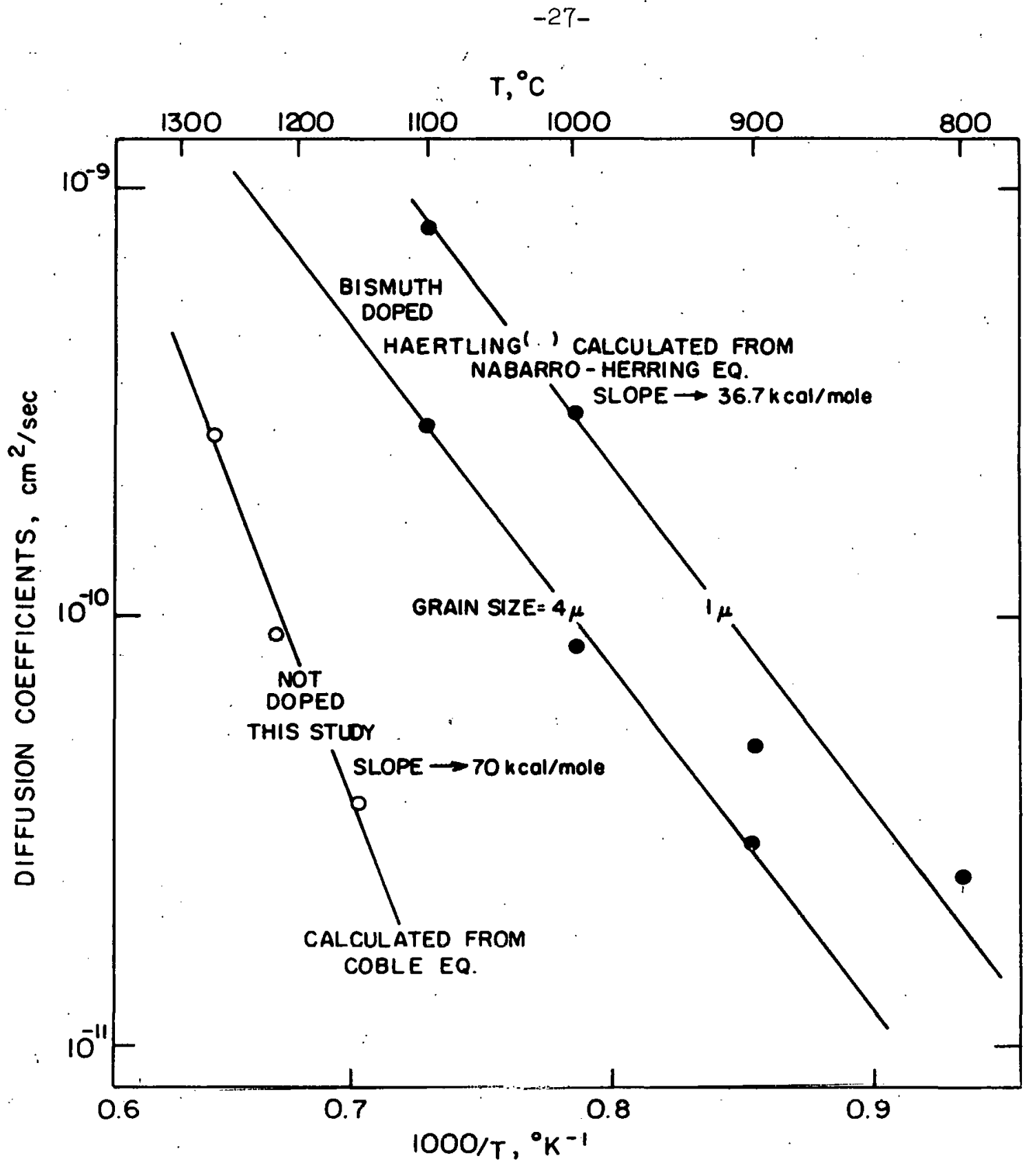

XBL 708-6445

Fig. 10. Arrhenius plot of diffusion coefficient. 
unaffected by these variations in stoichiometry (Fig. 9). This clearly indicates that the densification rate is independent of the concentration of A-site and B-site vacancies. Reducing the partial pressure of oxygen in the sintering atmosphere (i.e., increasing $\left[v_{C}\right]$ ) accelerated sintering (Fig. 9). These observations seem to indicate that oxyger vacaricies are the slowest moving species, and hence, rate limiting. $54-5,5$ Increasing their concentration increases the diffusional tlow and speeds aensification.

One might expect that doping with aluminum (forming additional oxygen vacancies) would increase the rate of diffusion and densification. Aluminum doping does enhance sintering, but it does so by retarding grain growth (Fig. 8). The absence of a precipitous increase in the effective diffusion coefficient is explained as follows: (1) the impurities are concentrated rear. graln boundaries and their presence upacto tho expected vacancy concentration gradient there, ${ }^{56}$ and (2) lhe vacalicies introduccd by doping are "bound" to the doping ions so they cannot move freely through the lattice to expedite mass transport.

Doping with ions of the incorrect valence generally retarded grain growth ard thereby enhanced sintering as shown in Fig. 8. Those data were oltained by hcating the cpecimens at $400^{\circ} \mathrm{C}$ per hnur tin $1.200^{\circ} \mathrm{C}$ and holding for the indicated time. The deviation of the curves from linearity indiates a change in densification kinetics. Unfortunately, the change was masked by the slow heating schedule; considerable sintering occurred before the specimens reached temperature.

The behavior of lead zirconate titanate doped with two atomic percent bismuth was studied in greater detail. This densification data 
(Fig. 11) was obtained with a very rapid heating anò cocling cycle in various oxygen and lead activity atmospheres. The positive deviation from linearity is still observed. The actual densification rates (at various times) were calculated from the sjope of these curves arid the values were plotted against the instantaneous grain size in Fig. 12. These curves show that the Coble equation is not obeyed and that the dersification rate of undoped lead zirconate titanate with $2 \mu$ grains would be fiive times faster than bismuth-doped material with the same grain size. The alteration of the grain-growth kiretics by doping was previously mentioned. The rate of densification does not appear to be sensitive to either the activity of lead or oxygen except when the lead activity is very low--presumably out of the single-phase region. This apparent insensitivity may be questionable, since densification of the bismuth-doped material was complete in a time much shorter than that required for equilibration with the atmosphere.

Densification is significantly changed by doping. The bismuth may reduce the oxygen diffusion sufficiently so that densification occurs by an alternate mechanism. 'Ihis would explain the change in kinetics. Alternatively the excess concentration of bismuth near grain boundaries will upset normal vacancy-concentration gradients and this perturbation should change the diffusion path. This alone may be sufficient to change the grain-size dependence of the densification rate.

\section{Ferroelectric Properties}

Measurements of the ferroelectric properties was a convenient method of characterizing the ceramics. 'l'he location of' impurities could be identified by their effect upon the ferroelectric hysteresis loops. Ions 


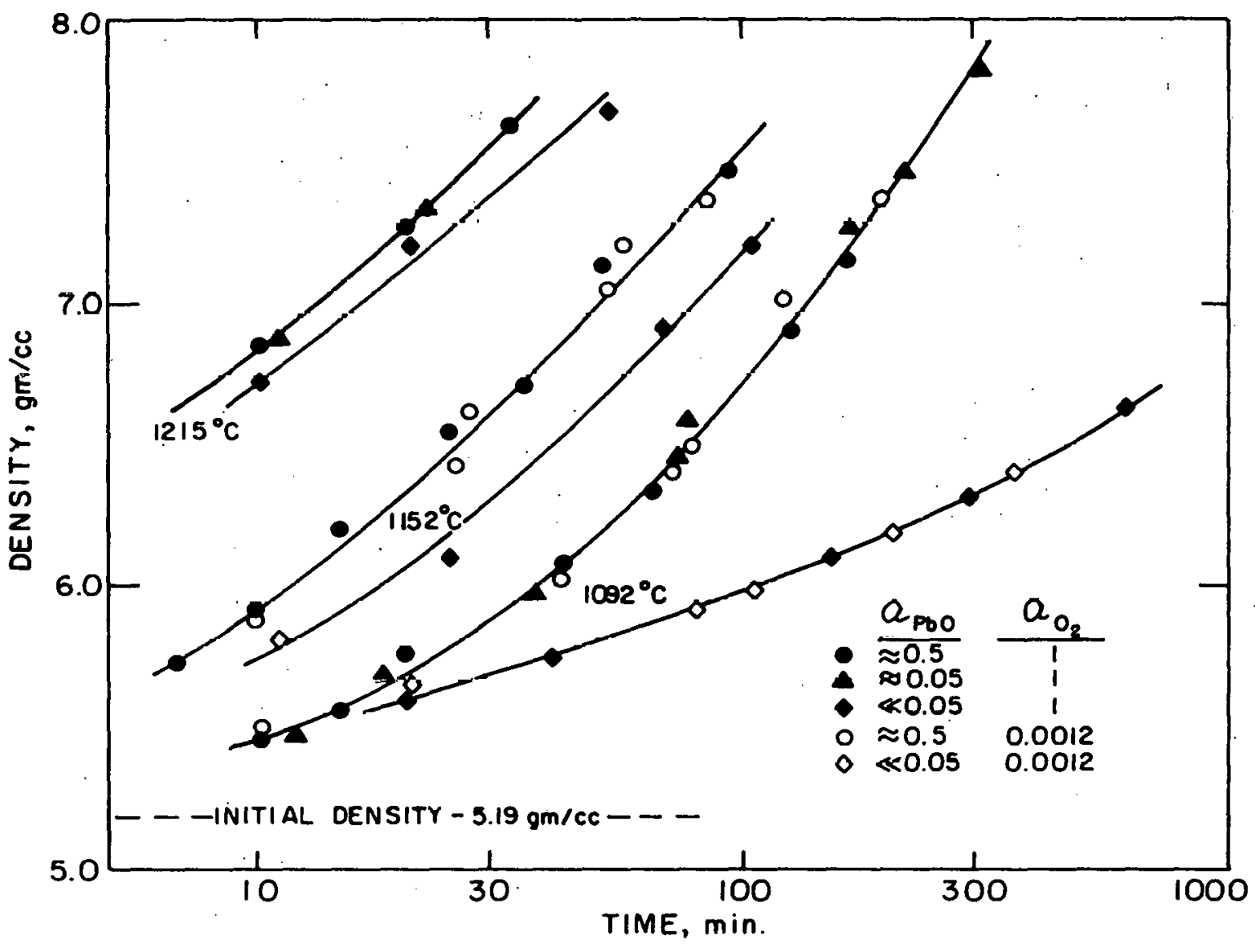

XBL $708-6446$

Fig. 11. Densification data for biamuth doped matcrial. 


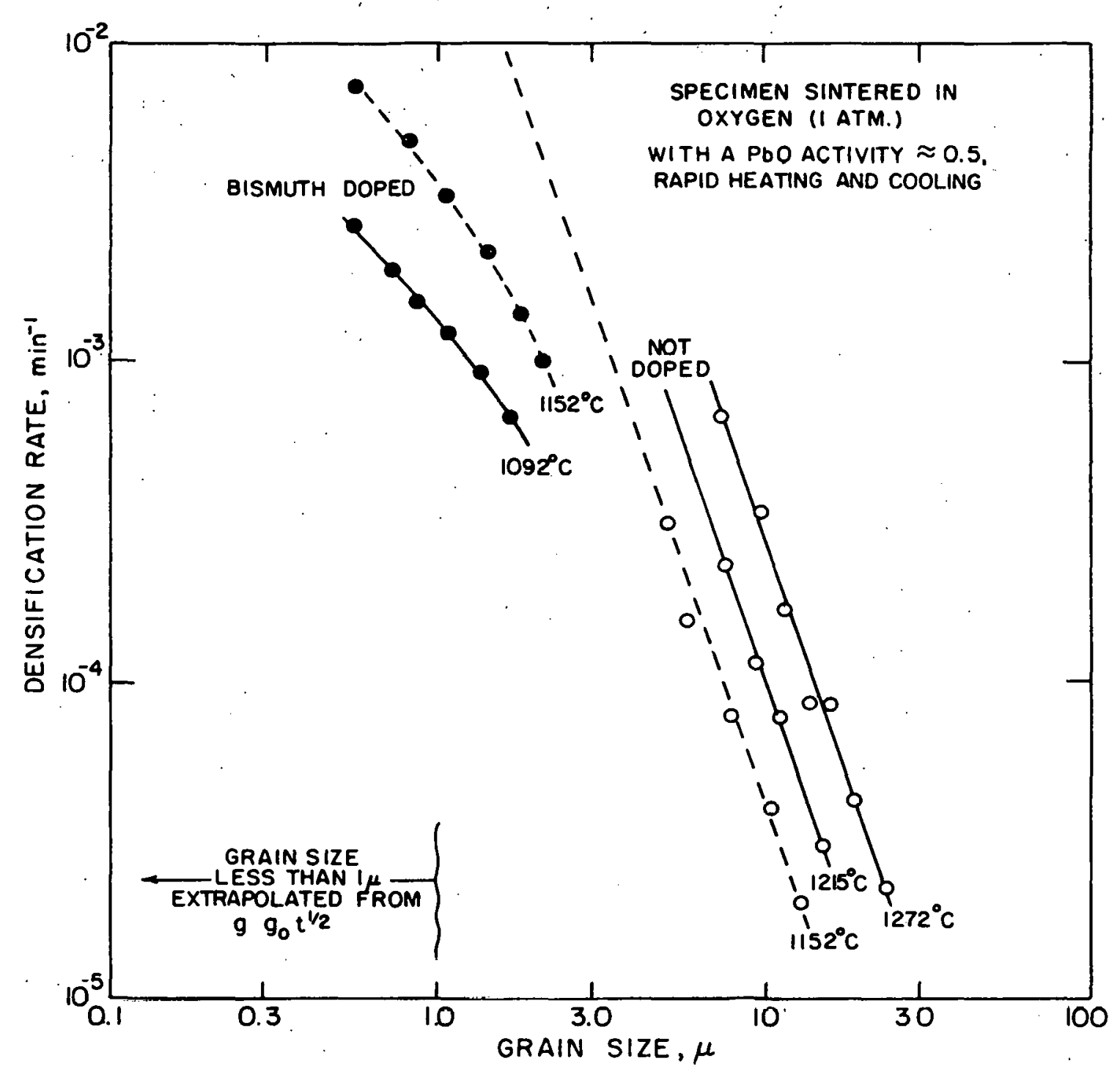

XBL 708-6444

Fig. 12. Densification rate vs grain size. 
with excess valence (bismuth, niobium) in solid solution produce square loops (Figs. 13 and 14), while substitutional ions with a deficient valence (aluminum and scandium ${ }^{57}$ ) yield materials of substantially reduced domain boundary mobility. These different types of doping ions may compensate each other (Fig. 13). When impurities are present in excess of saturation, the second phase may effect the ferroelectric properties. For example, silica additions increased those specimens' coercive field. The liquid phase covered each grain and, when cooled, this layer served as a serious capacitance with the ferroelectric grains (Figs. 14 and 15).

The ferroelectric properties were sensitive to the concentration of point defects. The specimen which had the greatest remnant polarization ( $48 \mathrm{microcoulomb} / \mathrm{cm}^{2}$ ) and the squarest hystercaio loop was produced hy rapidly cooling (from $1152^{\circ} \mathrm{C}$ to below $600^{\circ} \mathrm{C}$ in 10 seconds) fine grain, bismuth doped materials. The loop squareness and remnant polarization were both reduced by slow cooling. Annealing this material in an atmosphere of low lead or oxygen activity increased the remnant polarization. Rapidly cooling undoped samples also increased their ferroelectric activity. When dense undoped specimens were annealed at various temperatures and rapidly cooled, the remant polarization increased with annealing temperature. After annealing in low partial pressures of oxygen, the loops appeared more like those of the alumina-doped material. Annealing in low lead activity atmosphere had the opposite effect--the ferroelectric activity increased. The domain motion in aluminum-doped material was negligible, and annealing in various atmospheres had little et'tect. 

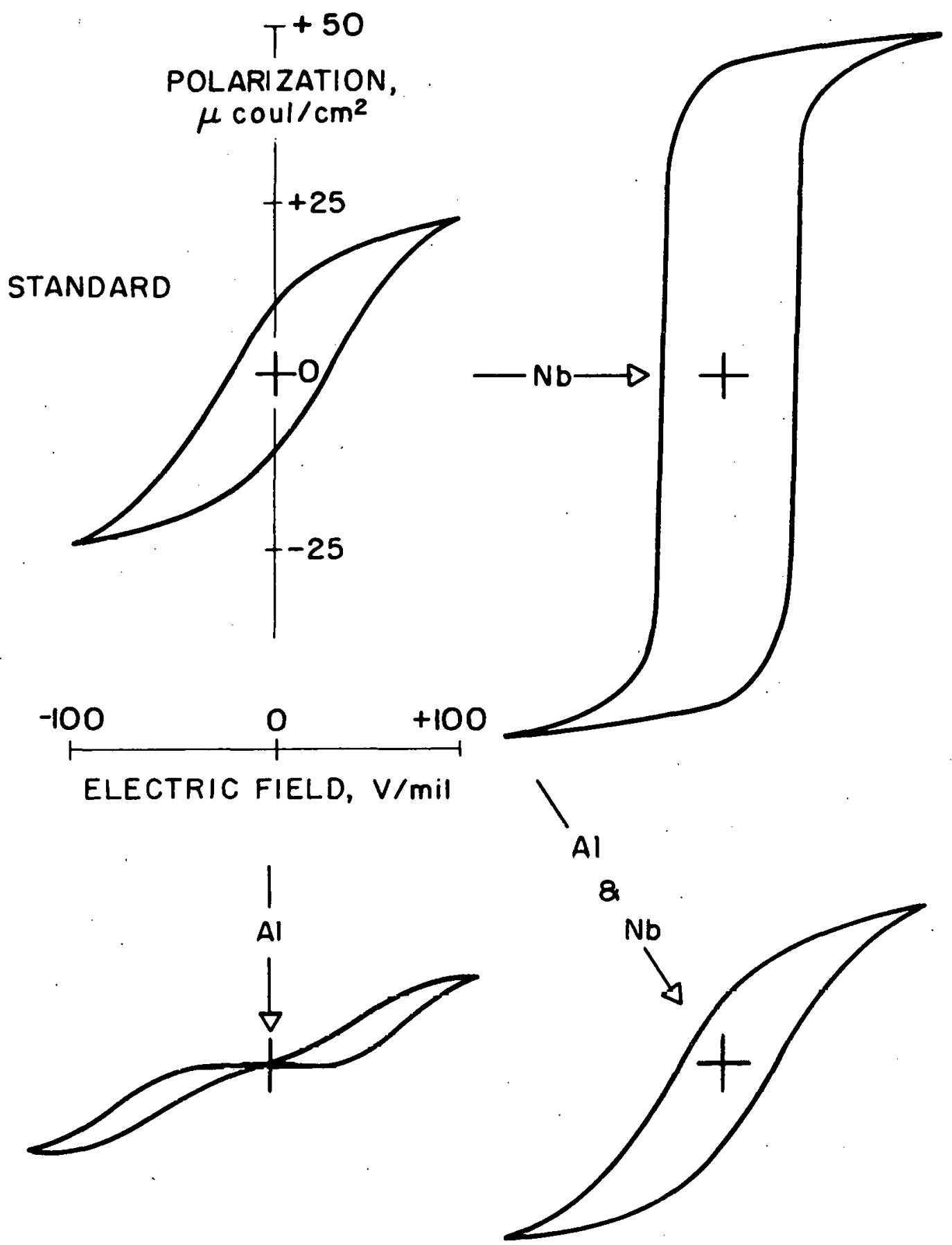

XBL $708-6443$

Fig. 13. Doping with niobium or aluminum alters the ferroelectric hysteresis loop: the effects are mutually cancelling.

Dielectric polarization is plotted as a function of electric field. 


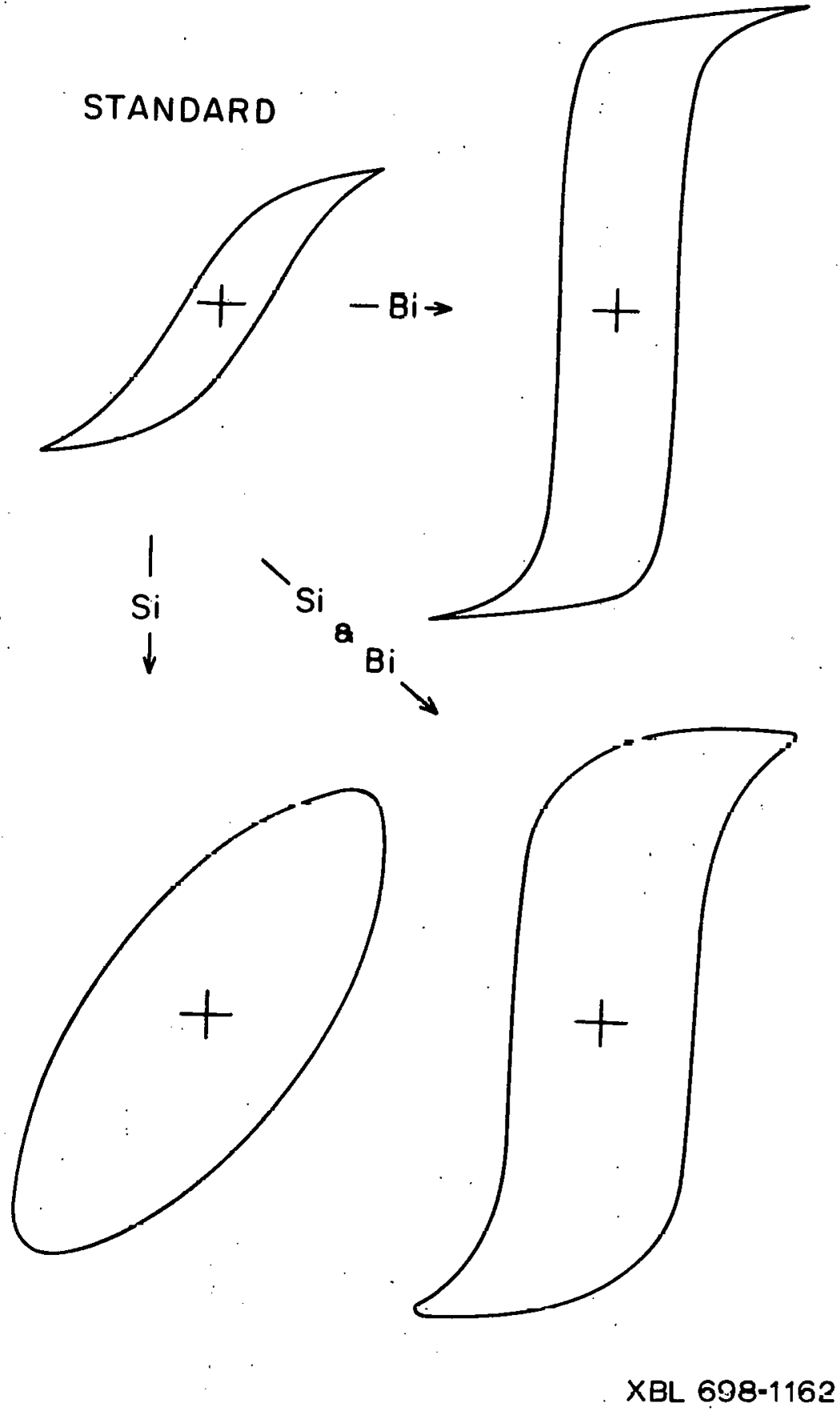

Fig. 14. The effects of bismuth and silica doping are additive. The scale is the same as in Fig. 13. 
PHYSICAL MODEL
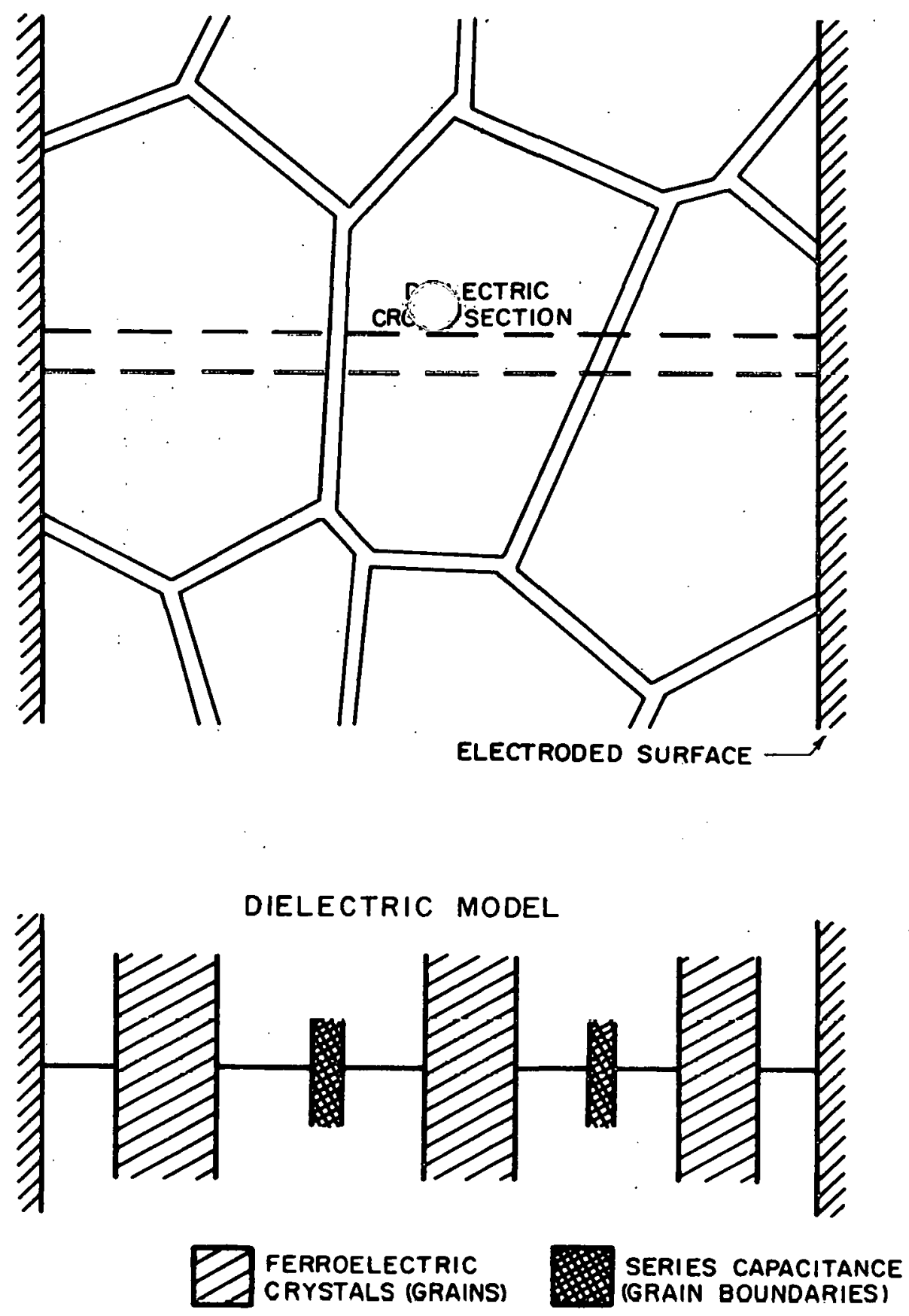

XBL 6812-6366

Fig. 15. Electric model of silicate glass phase at grain boundary. 
Generally, lead vacancies, particularly the charged ones associated with doping, produce square loops with extensive domain boundary motion. High concentrations of charged and uncharged oxygen vacancies yield a ferroelectric with quite immobile domain boundaries. Thus the desirable material to be used as a switching device would contain bismuth or niobium, be lieat treuled in an almusphere w1th a löw lead activity, and be cooled rapidly. On the other hand, a stable, low-loss ceramic for piezoelectric applications should be doped with alumina, scandium, chromium ${ }^{18}$ or iron. ${ }^{24}$ The device would be polarized above the curie temperature and cooled with the field applied. When operated near room temperature, domain boundary motion would not occur at moderate driving fields or stresses. Controlled reproducible properties are necessary for dil ferroelectric applications. To achieve this control, doping and impurity concentration levels must be fixed, the activity of oxygen and Thead in the sintering atmosphere must be controlled, and the cooling or subsequent heat-treatment schedules should not vary. 


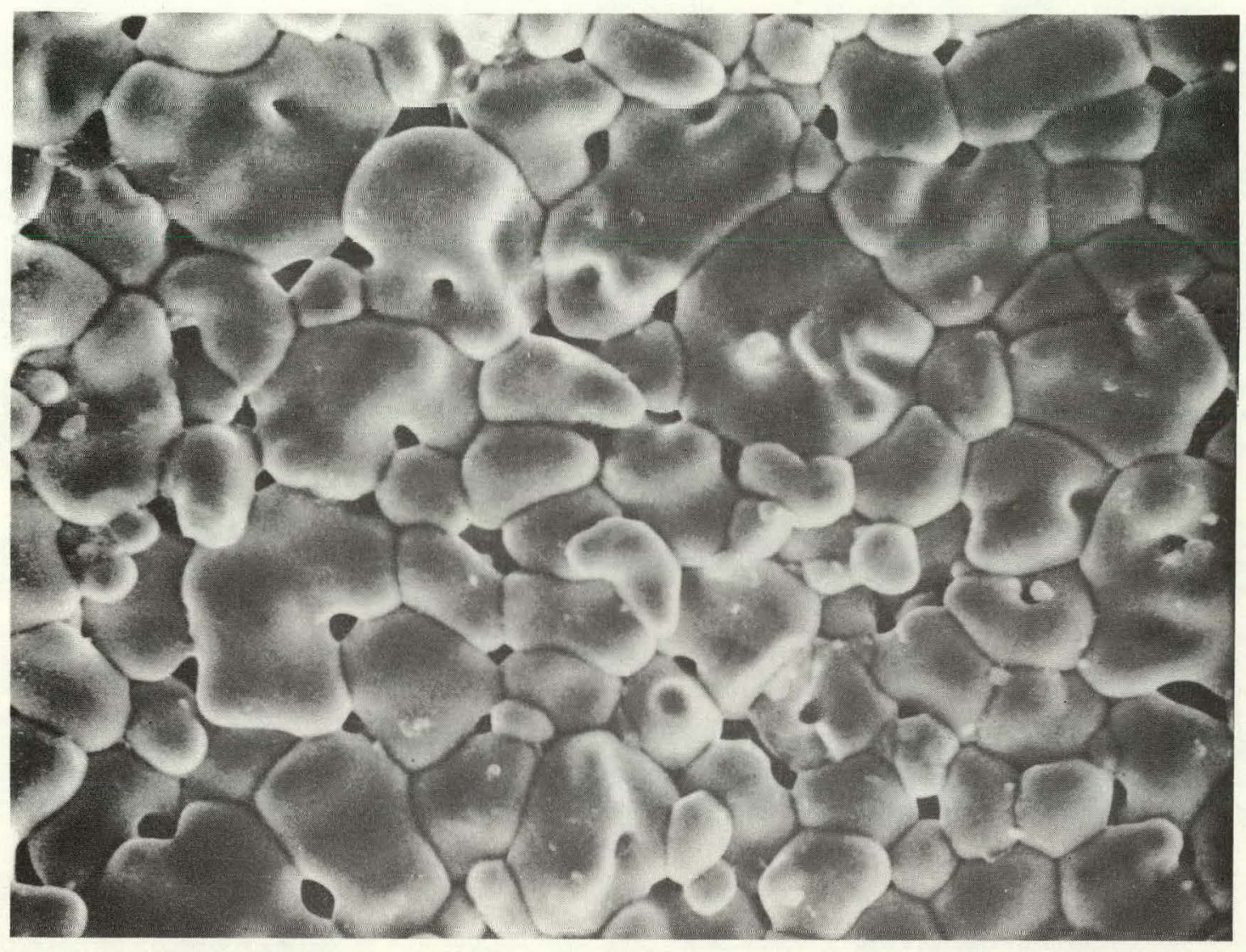

XBB 6810-6246

Fig. 16A. Scanning electron micrograph of thermally etch surface. Undoped material. 


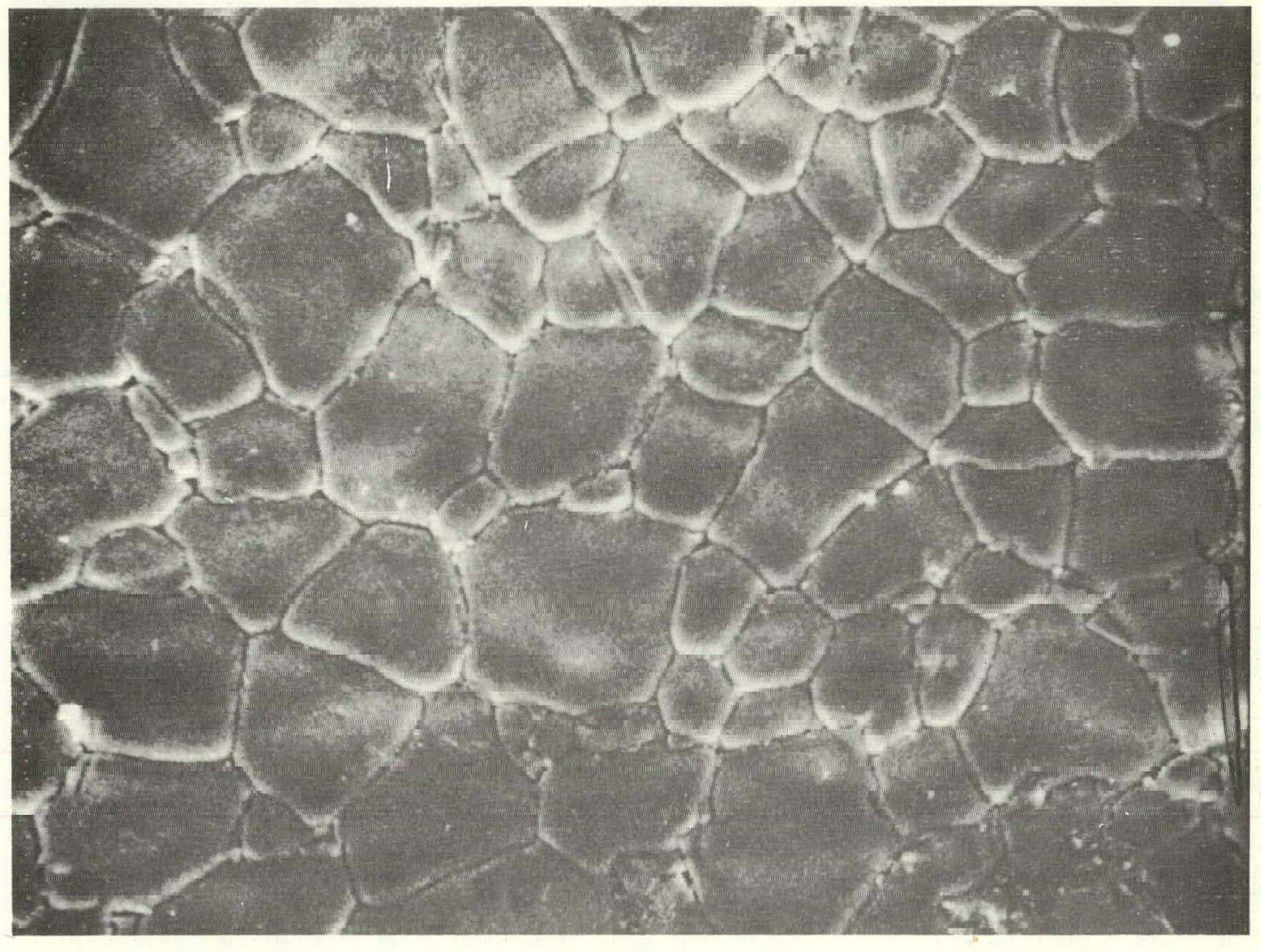

XBB 6810-6221

Fig. 16B. Scanning electron micrograph of thermally etched surface. Bismuth doped material. 


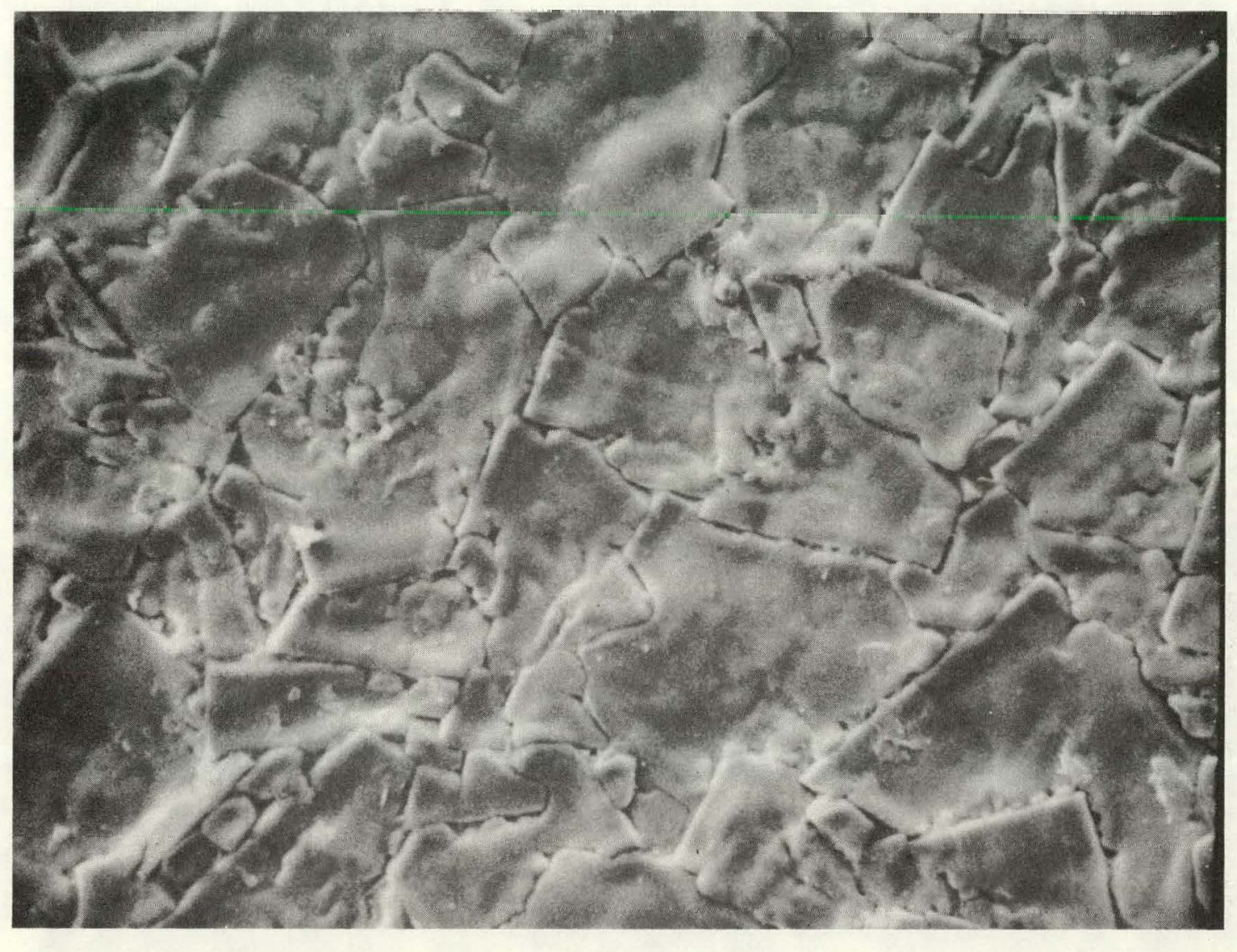

$$
\text { XBB 6810-6530 }
$$

Fig. 16C. Scanning electron micrograph of thermally etched surface. Material with boric oxide. 


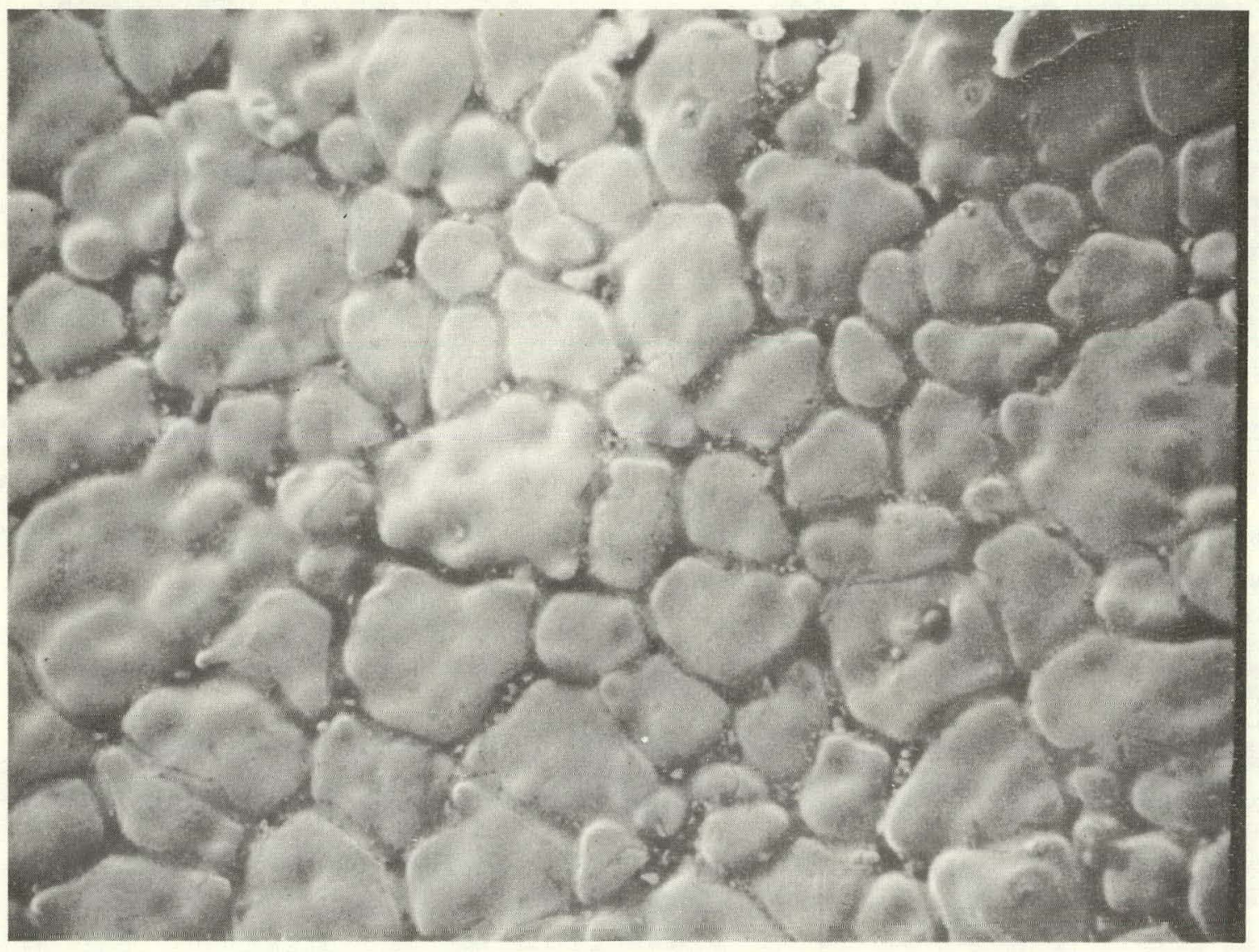

XBB $6810-6548$

Fig. 16D. Scanning electron micrograph of thermally etched surface. Material with silica. 


\section{SUMMARY AND CONCLUSIONS}

Single-phase lead zirconate titanate exists over a wide range of stoichiometry, corresponding to varying concentrations of lattice vacancies. The material can accommodate high concentrations of substitutional impurities which have the incorrect valence; local electroneutrality is maintained by charged lattice vacancies.

Undoped lead zirconate titanate sinters by the bulk diffusion of vacancies from pores to grain boundaries. Oxygen vacancies are believed to be the slowest diffusing species. The rate of sintering is insensitive to the concentration of uncharged lead vacancies, but it is accelerated by increasing the concentration of uncharged oxygen vacancies.

Substitutional impurities with the incorrect valence retard grain growth. The charged vacancies associated with these ions cause them to be adsorbed at grain boundarics. Then the moving boundary must drag along the excess concentration of impurities. This reduces its mobility and changes the grain-growth kinetics. Ions with an excess valence compensate for ions with a deficiency. Charged vacancies are not bound to either impurity, so they are not strongly adsorbed, and grain growth is not effectively impeded. The rate of grain growth is insensitive to the partial pressure of lead oxide and oxygen so long as the specimen remains single-phase. At very low lead oxide activities, grain growth is reduced, probably through grain boundary pinning by solid second phase particles.

Impurities enhance sintering by keeping the grain size small, thereby allowing densification to continue at a rapid rate. Bismuth doping decreases the apparent diffusivity, but the grain-size effect is 
far more important. Doping alters the densification kinetics, but this does not necessarily indicate a basic change in the sintering mechanism. Lattice: vacancies dramatically change the ferroelectric behavior. The charged lead vacancies introduced by doping increase the domainboundary mobility and produce square hysteresis loops. Charged oxygen vacancies reduce boundary motion and gi've "propeller-shaped" loops. Compensatory doping eliminates both types of charged vacancies and yields a ferroelectric loop like that of the undoped material. The uncharged. vacancies produced by reducing the lead and/or oxygen activity have only a second-order effect upon the ferroelectric properties.

Thus control of the ultimate ceramic properties requires precise control over the type and concentration of impurities, maintenace of the correct atmosphere during sintering, and reproducible heat-treatment s chedules. 


\section{$-43-$ \\ ACKN OWLEDDGMENTS}

The guidance of Professor Richard Fulrath is gratefully acknowledged as are the many helpful discussions with Dr. Paul Jorgensen and fellow. graduate students. Thanks for experimental assistance are due Rand Unverferth, Mike Neminic, John Lawson, George Scherer, Robert Holman and John Sherohman.

The author wishes to express appreciation for the use of the scanning electron microscope within the Electronics Research Laboratory, University of California, provided under Grant No. GB-6428 from the National Science Foundation and under Grant No. GM-15536 from the National Institute of Health.

This work was done under the auspices of the United States Atomic Energy Commission. 


\section{$-44-$}

\section{REFERENCES}

1. B. Jaffe, R. S. Roth and S. Marzullo, "Properties of Piezoelectric Ceramics in the Solid-Solution Series Lead Titanate-Lead ZirconateLead Oxide: Tin Oxide and Lead Titanate-Lead Hafnate," J. of Research of the National. Bureau of Standards, 55 [5] 239-53 (1955).

2. Gene Hertling, "Hul,-Pressen Ferroelectric Laad zirconatc Titanate for Electro-Optical Applications," Am. Ceram. Soc. Bu1.1., 49 [6] $264-7(.1970)$

3. A. J. Parisi, "Ceramic 'Solid-State' Imaging Leaps into Development State," Product Engineering, 13-15, May 25, 1970.

4. C. E. Land and P. D. Thacher, "Ferroelectric Ceramic Electro-optic Materials and Devices," Proc. IEEE, 57 [5] (1969). A]sn see IEEE Trans on E'lect. Devices, Vol. ED-16 No. 6 (1969).

5. G. W. Taylor, "Electrical Propcrties of Niobium-Doped Ferroelectric $\mathrm{Pb}(\mathrm{7r}, \mathrm{Sn}, \mathrm{Ti}) \mathrm{O}_{3}$ Ceramics," J. Appl. Phys., 38 [12] 4697-704 (1967).

6. D. W. Chapman, "Some Thin-film Properties of a New Ferroelectric Composition," J. Appl. Phys., 40 [6] 2381-85 (1969).

7. Gene J. HaertIing, "Hot-Pressed Lead Zirconate-Titanate-Stannate Ceramics," J. m. Ceram. Soc: 42 [11] 679-84 (1963).

8. Gene H. Haerthing. "Hot-Pressed Tread Zirconate-Lead Titanatc Ccramica Containing Bismuth," J. Am. Ceram. Soc., 느 [12] 875-9 (1964).

9. Gene H. Haertling, "Grain Growth and Densification of Hot-Pressed Lead Zirconate-Lead Titanate Containing Bismuth," J. Am. Ceram. Soc., 49 [3] $113-8(1966)$.

10. Bruce Semans, "Densification and Electrical Properties of Lead Zirconate-Titanate," M.S. Thesis, Univ. of Calif., Berkeley, 1968 (UCRI-18126). 
11. Peter D. Levett, "Factors Affecting Lead Zirconate-Lead Titanate Ceramics," Am. Ceram. Soc. Bul1: 42 [6] 348-52 (1963).

12. A. H. Webster, T. B. Weston and N. F. H. Bricht, "Effect of PbO Deficiency on the Piezoelectric Properties of Lead ZirconateTitanate Ceramics," J. Am. Ceram. Soc. 50 [9] 490-1 (1967).

13. E. C. Subbarao, "Studies on Lead Titanate Ceramics Containing Niobium or Tantalum," J. Am. Ceram. Soc: 43 [3] 119-22 (1960).

14. Robert Gerson, "Variation in Ferroelectric Characteristics of Lead Zirconate Titanate Ceramics Due to Minor Chemical Modifications," J. Appl. Phys: 31 [1] 188-94 (1960).

15. R. H. Dungan, H. M. Barnett and A. H. Stark, "Phase Relations and Electrical Parameters in the Ferroelectric-Antiferroelectric Region. of the System $\mathrm{PbZrO}_{3}-\mathrm{PbTiO}_{3}-\mathrm{PbNb}_{2} \mathrm{O}_{6}$," J. Am. Ceram. Soc. 45 [8] $382-8(1962)$.

16. T. Ikeda and T. Okano, "Piezoelectric Ceramics of Lead ZirconateTitanate Modified by Bismuth Ferrite," Japan J. Appl. Phys. $\underline{2}$, 63-4 (1963)

17. T. Ikeda and T. Okano, "Piezoelectric Ceramics of $\mathrm{Pb}(\mathrm{Zr}-\mathrm{Ti}) \mathrm{O}_{3}$ Modified by $\mathrm{A}^{1+} \mathrm{B}^{5+} \mathrm{O}_{3}$ or $\mathrm{A}^{3+} \mathrm{B}^{3+} \mathrm{O}_{3}$," Japan J. Appl. Phys., 3 [2] 63-71 (1964).

18. N. Uchida and T. Ikeda, "Studies on $\mathrm{Pb}(\mathrm{Ar}-\mathrm{Ti}) \mathrm{O}_{3}$ Ceramics with Additions of $\mathrm{Cr}_{2} \mathrm{O}_{3}$," Japan J. Appl. Hhys., $\underline{6}$ [11] 1292-99 (1967).

19. I. Veda and S. Ikegami, "Piezoelectric Properties of Modified $\mathrm{PbTiO}_{3}$ Ceramics," Japan J. Appl. Phys: I [3] 236-42 (1968).

20. Frank Kulcsar, "Electromechanical Properties of Lead Titanate Zirconate Ceramics with Lead Partially Replaced by Calcium or Strontium," 
J. Am. Ceram. Soc.; 42 [1] 49-51 (1959).

21. Frank Kulcsar, "Electromechanical Properties of Lead Titanate Zirconate Ceramics Modified with Certain Three or Five-Valent Additions," J. Am. Ceram. Soc., 42 [7] 343-49 (1959).

22. T. Ikeda, Y. Tanaka, T. Ayakawa and H. Noake, "Precipitation of Zir-

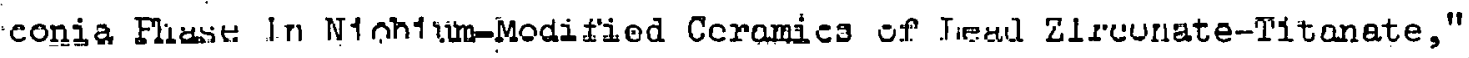
Japan J. Appil. Phys.: 3 [10]. 581-87 (1964).

23. H. Banno and T. Tsunooka, "Piezoelectric Properties and Temperature Dependences of Resonant Frequency of $\mathrm{WO}_{3}-\mathrm{MnO}_{2}-$ Modified Ceramics of $\mathrm{Pb}(\mathrm{Zr}-\mathrm{Ti}) \mathrm{O}_{3}$," Japan J. Appl. Phys., 6 [8] 954-62 (1967).

24. T. B. Weston, A. H. Webster and V. M. McNamara, "Lead ZirconateLead Titanate Piezoelectric Ceramics with Iron Oxide Additions," J. Am. Ceram. Soc.; 52 [5] 253-57 (1969).

'5. Gary A. Pryor, "Impurity Effects in S1ntering Lead Zirconate Titanate," M.S. Thesis, Univ. of Calif., Berkeley, 1968 (UCRI-18191).

26. K. E. Nelson and R. I. Cook, "Effect of Contamination Introduced During Wet Milling on the Electrical Properties of Barium Titanate," Am. Ceram. Soc. Bull: 38 [10] 499-500 (1959).

27. A. H. Webster, "The Sintering Characteristics of Precipitated Mixed Hydroxides nf Lead; Ziroonium and Titanium," Depl. of Mines and Technical Surveys, Mines Branch Investigation Report IR 62-45, June 27, 1962, Ottawa, Canada.

28. R. Gerson and T. C. Marshall, "Dielectric Breakdown of Porous Ceramics," J. App. Phys.; 30 [11] (1959).

29. A: H. Webster, "The Effect of Some Fabrication Conditions on the Properties of Lead Zirconate Titanate," Dept. Of Mines and Technical 
Surveys, Mines Branch Investigation Report IR 63-59, July 9, 1963, Ọttawa, Canada.

30. R. B. Atkin and R. M. Fullrath, "Solubility of Aluminum in Lead Zirconate Titanate," J. Am. Ceram. Soc.; 53 [1] 51-2 (1970).

31. R. B. Atkin, R. I. Holman and R. M. Fulrath, "Ionic Substitutions in Lead Zirconate-Titanate," Submitted to J. Am. Ceram. Soc. Aug 1970 (UCRL-19632).

32. R. B. Atkin and R. M. Fulrath, "The Practical Aspects of Sintering,". in Interfaces Butterworth Publishing Co., Melbourne, Australia (1969). Also see UCRL-18795.

33. R. L. Fullman, "Measurement of Particle Sizes in Opaque Bodies," Trans. AIME; $197 \cdot[3] .447-52$ (1953).

34. E. R. Stover, Private communication to C. A. Bruch, as cited in "Sintering Kinetics for the High Density Alumina Process," J. Am. Ceram. Soc.; 41 [12] 799-804 (1962).

35. Hans Jaffe, "Properties of Ferroelectric Ceramics in the Lead- : Titanate Zirconate System," Presented at the International Conference on Components and Materials Used in Electronic Engineering, The Institution of Electrical Engineers Peper No. 3625, June 1961.

36. Ronald Moon, "High Temperature Phase Equilibria in the Lead TitanateLead Zirconate System," Ph.D. Thesis, Univ. of Calif. Berkeley, 1967 (UCRL 17545).

37. K. H. Hardtl and H. Rau, "PbO Vapour Pressure in the $\mathrm{Pb}\left(\mathrm{Ti}_{1-\mathrm{x}} \mathrm{Zr}_{\mathrm{x}}\right) \mathrm{O}_{3}$ System," Solid State Communications; 1 41-5 (1969).

38. S. Fushimi and T. Ikeda, "Phase Equilibrium in the System $\mathrm{PbO}-\mathrm{TiO}_{2}-$ $\mathrm{ZrO}_{2}, " \mathrm{~J}$. Am. Ceram. Soc., 50 [3] $129-32$ (1967). 
39. A. F. Welis, Structural Inorganic Chemistry, Oxford University Press, London (1962).

40. J. E. Burke, "Recrystallization and Sintering in Ceramics;" in Ceramic Fabrication Processes, Edited by W. D. Kingery, the M.I.T. Press, Cambridge, Mass. (1963).

41. G. W. Greenwond, "The Growth of Dispereed Prccipitates in Solutiuns," Acta Met. 4 243-8 (May 1956).

42. W. D. Kingery arld B. Francois, "Grain Growth in Porous Compacts," J. Am. Ceram. Soc: 48 [10] 546-7 (1965).

43. F. A. Nichols, "Theory of Grain Growth in Porous Compacts," J. Appl. Phys., 37 [13] 4599-602 (1966).

44. T. M. Havkviich, J. Magder, M. S. Vukasovich and R. J. Lockhart, "Forroelectrico of Ultrafine Pailicle 3ize: II, Grain Growth Inhibition Studies," J. Am. Ceram. Soc, : 49 [6] 29.5-9 (19,6h).

45. W. R. Bratchun, "Sintering of Doped and Undnper Rarium Titanate," J. Am. Ceram. Soc: 45 [12] 611-12 (1962).

46. P. Gordon and R. A. Vandermeer, "The Mechanism of Boundary Migration in Recrystallization," Trans. Met. Soc. AIME; 224917 (Oct 1962).

47. K. Lucke and K. Detert, "A Quantitative Theory of Grain Boundary Motion and Recrystallization in Metals in the Presence of Impuriticn," Acta. Met: 5 628-37 (Nov 1957).

48. E. S. Machlin, "Theory of Sulute Atom Limited Grain Boundary Migration," Trans. Met. Soc. AIM: 224 1153-67 (Dec 1962).

49. P. J. Jorgensen, "Modification of Sintering Kinetics by Solute Segregation in $\mathrm{Al}_{2} \mathrm{O}_{3}, "$ " J. Am. Ceram. Soc: 48 [4] 207-10 (1.965). 
50. P. J. Jorgensen and J. H. Westbrook, "Role of Solute Segregation at Grain Boundaries During Final-Stage Sintering of Alumina," J. Am. Ceram.' Soc,; 47 [7] $332-38 \cdot(1964)$.

51. P. J. Jorgensen and R. C. Anderson, "Grain-Boundary Segregation and Final-Stage Sińtering of $\mathrm{x}_{2} \mathrm{O}_{3}, " \mathrm{~J}$. Am. Ceram. Soc: 50 [11] 553-8 (1967).

52. R. L. Coble, "Sintering Crystalline Solids. I. Intermediate and Finald Stage Diffusion Models," J. Appl: Phys: 32 [5] 787-92 (1961).

53. R. L. Coble and T. K.Gupta, "Intermediate Stage Sintering" in Sintering and Related Phenomena, Edited by Kuczynski, Hooton and Gibbon, Gordon and Breach Science Publishers, New York (1967).

54. Paul J. Jorgensen, "Diffusion: Controlled Sintering in Oxides," Sintering and Related Phenomena, Edited by Kuczynski, Hooton and Gibbon, Gordon and Breach Science Publishers, New York (1967).

55. R. L. Coble, "Sintering Alumina: Effect of Atmosphere," J. Am. Ceram. Soc: 45 [3] 123-7 (1962).

56. Paul Jorgensen, Private communication.

57. Douglas Lee, "Sintering Sc and Nb Modified Lead Zirconate Titanate, M. S. Thesis, Univ, of Calif. Berkeley, 1970 (UCRL-19188). 


\section{LEGAL NOTICE}

This report was prepared as an account of Government sponsored work. Neither the United States, nor the Commission, nor any person acting on behalf of the Commission:

A. Makes any warranty or representation, expressed or implied, with respect to the accuracy, completeness, or usefulness of the information contained in this report, or that the use of any information, apparatus, method, or process disclosed in this report may not infringe privately owned rights; or

B. Assumes any liabilities with respect to the use of, or for damages resulting from the use of any information, apparatus, method, or process disclosed in this report.

As used in the above, "person acting on behalf of the Commission" includes any employee or contractor of the Commission, or employee of such contractor, to the extent that such employee or contractor of the Commission, or employee of such contractor prepares, disseminates, or provides access to, any information pursuant to his employment or contract with the Commission, or his employment with such contractor. 
$=$ 